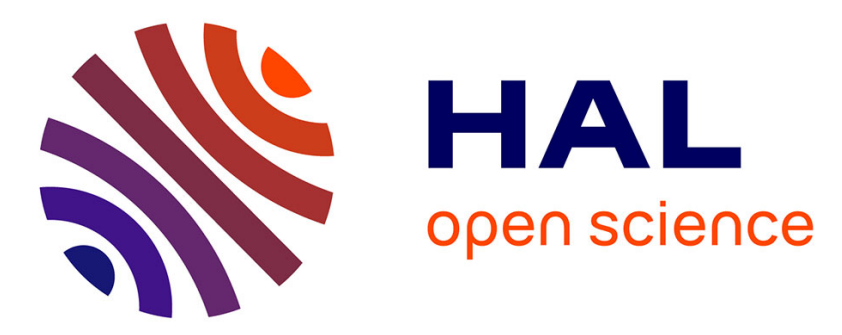

\title{
A review about the fluorination and oxyfluorination of carbon fibres
}

Jean Charles Agopian, Olivier Teraube, Karine Charlet, Marc Dubois

\section{To cite this version:}

Jean Charles Agopian, Olivier Teraube, Karine Charlet, Marc Dubois. A review about the fluorination and oxyfluorination of carbon fibres. Journal of Fluorine Chemistry, 2021, 251, pp.109887. 10.1016/j.jfluchem.2021.109887 . hal-03474362

\section{HAL Id: hal-03474362 \\ https://hal.uca.fr/hal-03474362}

Submitted on 15 Dec 2021

HAL is a multi-disciplinary open access archive for the deposit and dissemination of scientific research documents, whether they are published or not. The documents may come from teaching and research institutions in France or abroad, or from public or private research centers.
L'archive ouverte pluridisciplinaire $\mathbf{H A L}$, est destinée au dépôt et à la diffusion de documents scientifiques de niveau recherche, publiés ou non, émanant des établissements d'enseignement et de recherche français ou étrangers, des laboratoires publics ou privés. 


\section{Table of contents}

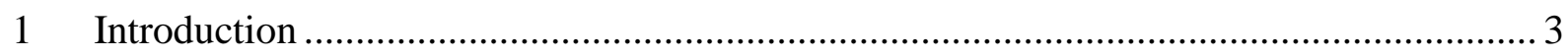

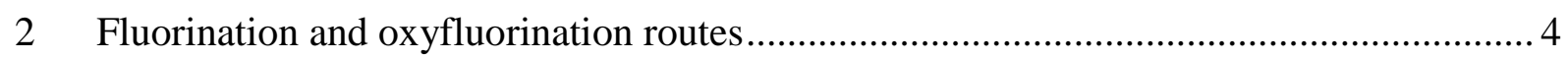

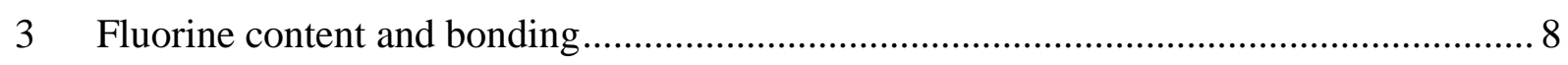

3.1 Study of the carbon fibre surface before the (oxy)fluorination treatment .................. 8

3.2 Study of the (oxy)fluorinated carbon fibre surface ............................................ 10

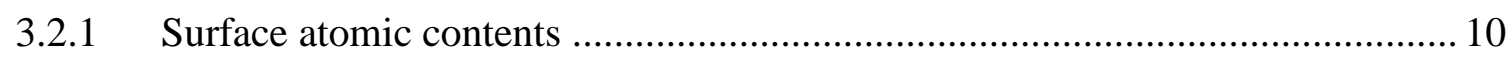

3.2.2 C-F bonding at the carbon fibre surface and fluorination mechanisms ............. 13

4 Morphological and surface properties induced by fluorination ..................................... 19

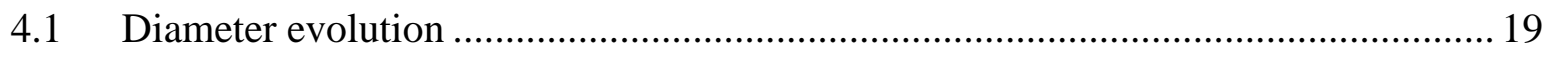

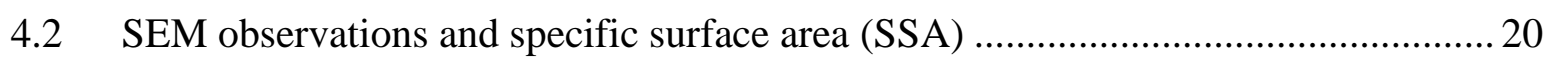

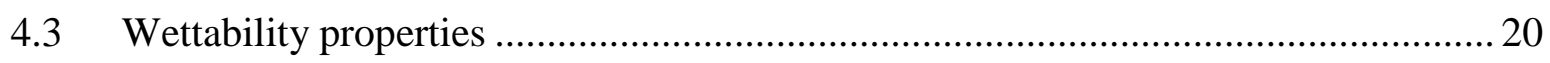

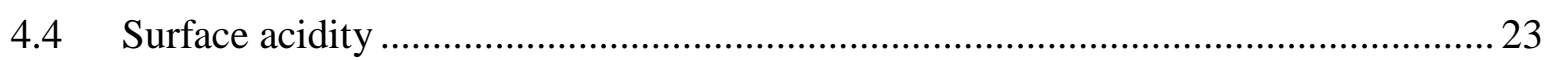

5 Structural and bulk properties induced by fluorination............................................. 24

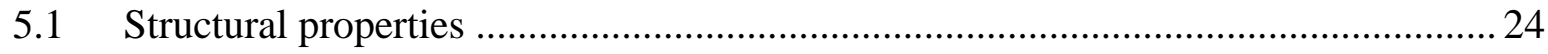

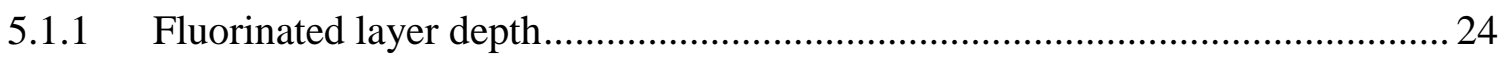

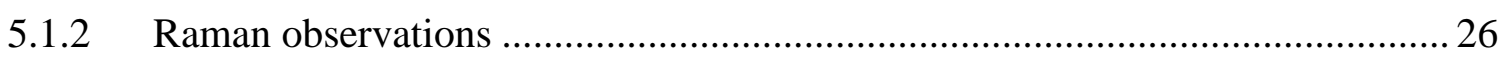

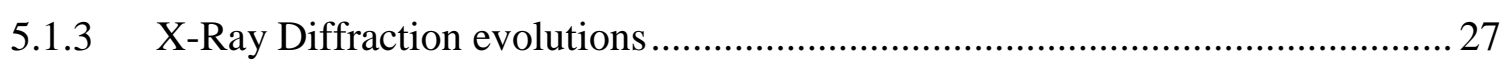

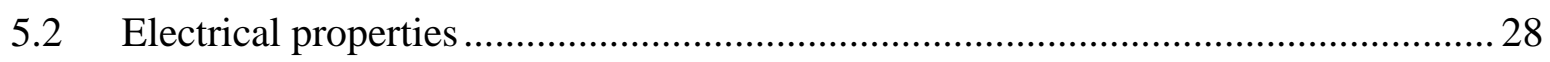

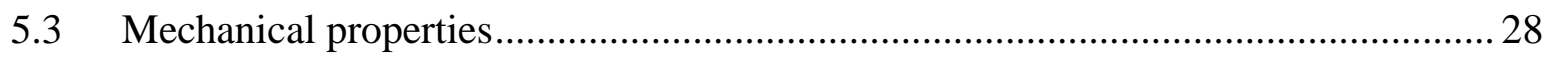

5.4 Potential applications for (oxy)fluorinated materials ...............................................29

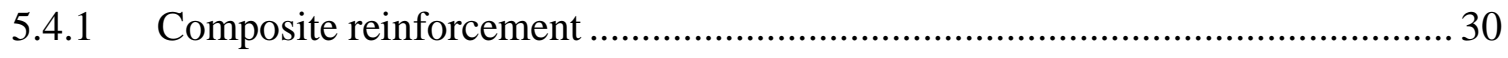

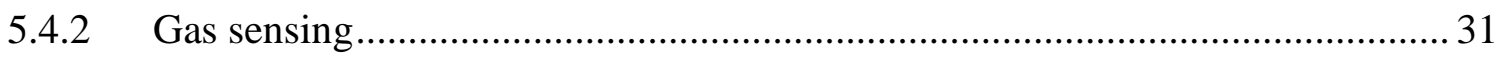

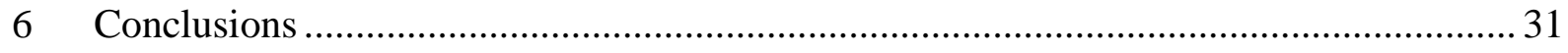

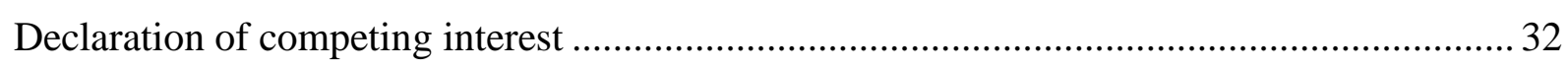

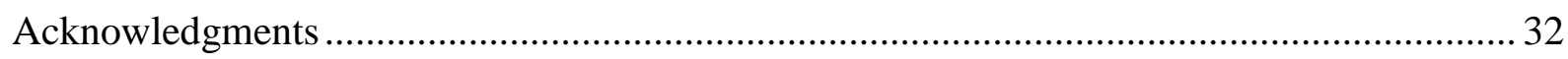

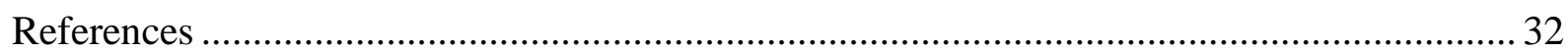




\title{
A review about the fluorination and oxyfluorination of carbon fibres
}

\author{
Jean-Charles Agopian*a, Olivier Téraube ${ }^{\mathrm{b}}$, Karine Charlet ${ }^{\mathrm{a}}$, Marc Dubois ${ }^{\mathrm{b}}$
}

*: corresponding author. Phone number: +33675182245.

${ }^{a}$ Université Clermont Auvergne, Clermont Auvergne INP, CNRS, Institut Pascal, F-63000 Clermont-Ferrand, France. Mail: \{jean-charles.agopian; karine.charlet\}@ sigma-clermont.fr

${ }^{\mathrm{b}}$ Université Clermont Auvergne, Clermont Auvergne INP, CNRS, ICCF, F-63000 ClermontFerrand, France. Mail: \{olivier.teraube; marc.dubois\} @uca.fr

\begin{abstract}
Depending both on structure and properties of the starting carbonaceous material, and on the fluorination conditions, fluorine can bond to carbon fibres in various ways. This review aims to investigate the versatility of the $\mathrm{C}-\mathrm{F}$ bonding and its influence on the fibre properties. Morphology and surface properties, such as diameter, Scanning Electron Microscopy observations, specific surface area, wettability and surface acidity are discussed according to the fluorine content and the fluorination route. Structural and bulk properties of fluorinated carbon fibres, regarding Raman spectroscopy, X-ray diffraction analysis, electrical and mechanical properties, and bonding with polymers are also studied. 114 papers are reviewed in order to both extract general trends on those characteristics and highlight applications as fillers in composites and sensitive materials in gas sensing.
\end{abstract}

Keywords: Fluorination; Oxyfluorination; Carbon fibers; Surface and Bulk Properties; XPS; Wettability. 


\section{Introduction}

Carbon fibres are known to be high-strength materials, which offer one of the highest Young moduli (up to $760 \mathrm{GPa}$ ) and strengths (up to $5.65 \mathrm{GPa}$ ) amongst reinforcing fibres. They are often used as reinforcement materials for composites in several fields such as aerospace, nuclear and transport $[1,2]$. However, in order to exploit the outstanding mechanical properties of carbon fibres in composites, the adhesion at the interface between the fibres, which support the stress, and the matrix, which distributes it, has to be optimised [3]. As carbon fibres are known to be highly inert materials due to their graphitic structure [4], their surface has to be functionalised to achieve maximal stress-transfer properties.

Numerous ways of functionalisation have already been successfully developed in literature for carbon fibres. The most known are based on oxidative treatments [5-7], plasma treatments $[8,9]$, electrografting [10,11], or chemical grafting of oxygenated [12] or nitrogenated $[4,13-$ 15] species. Other innovative and promising methods exist, such as microwave irradiation [16,17], metal oxide coating [18,19], or bio-inspired functionalisation [20,21]. Independently of the retained method, similar trends are observed: fibre tensile properties are maintained, while fibre wetting with resin, interfacial shear strength (IFSS), and fibre-based composite tensile strength are improved.

Another well-known way to functionalise carbonaceous materials is fluorination. This treatment offers interesting advantages over other surface modification methods:

- Direct fluorination is a dry process, meaning that it does not require use and storage of often toxic solvents. Moreover, optimised fluorination conditions lead to a low ecological footprint treatment, without human contact with the reactant [22].

- Safe methods exist to neutralise residual $\mathrm{F}_{2}$ and fluorinated end-products in the fluorination reactor [23], e.g. soda lime trap.

- Fluorination requires a strict control of the experimental conditions. It is both a difficulty (as discussed later) and an advantage, because it allows to reach controllable and repeatable properties on fluorinated materials.

- The versatility of the C-F bond nature, that will be discussed later too, is also a difficulty and an advantage at the same time: it allows to reach an extraordinary diversity of properties for fluorinated materials, but requires a good comprehension and control of the experimental conditions and starting material.

- Most fluorination processes may be performed at the industrial scale, as proved by the fluorination of car tanks [24].

- If fluorination occurs at room temperature (RT), it is a low energy consuming reaction. Independently of the reaction temperature, as fluorine is highly reactive, it is a quick surface modification method.

Fluorinated carbons own highly interesting properties, such as chemical stability, tunable bandgap, good thermal conductivity, or super-hydrophobicity [25]. However, the comprehension of the phenomena at stake during the fluorination treatment can be complex, due to both the versatility of the C-F bond nature [26] and the large panel of fibre precursor properties, such as crystalline order, specific surface area, texture, or morphology [27]. Both the structure and properties of starting material, as well as the chosen fluorination conditions, for instance temperature, pressure or duration, can explain this versatility [28], which will be highlighted all along this review. Moreover, the presence of oxygen atoms also plays a key role. The properties conferred by fluorination to carbon fibres, such as wettability, structural evolution or mechanical properties, will indeed depend of the $\mathrm{C}-\mathrm{F}$ bond nature, which can be 
evidenced using either X-ray photoelectron spectrometry (XPS) or solid state Nuclear Magnetic Resonance considering ${ }^{19} \mathrm{~F}$ and/or ${ }^{13} \mathrm{C}$ nuclei $[29,30]$.

As a matter of fact, this review aims to sum up the main findings that have been reported in works about the fluorination and oxyfluorination of carbon fibres. How fluorine atoms graft to the fibre surface will be investigated first, before going further on the study of surface and bulk properties induced by (oxy)fluorination treatments.

\section{Fluorination and oxyfluorination routes}

The grafting of fluorine atoms onto the surface of the fibres or into their bulk requires the use of a strong oxidant such as molecular fluorine $\left(\mathrm{F}_{2}\right)$, for which the reactivity may be either decreased by dilution with an inert gas (e.g., $\mathrm{He}, \mathrm{N}_{2}$ ) or increased in gaseous mixture with $\mathrm{HF}$ or $\mathrm{O}_{2}$. The reactive gas or its mixture may be introduced either in dynamic mode with a continuous flux in an opened reactor (always passivated with $\mathrm{NiF}_{2}$ coating and linked to a trap to remove the excess of $\mathrm{F}_{2}$ and side products such as $\mathrm{CF}_{4}, \mathrm{C}_{2} \mathrm{~F}_{6}, \mathrm{HF}, \mathrm{OF}_{2}$ according to the chemical composition of the precursor) or in a static mode. In this latter case, a defined amount of gas is introduced in a closed passivated reactor (the trap is then useful at the end of the process during the flush with an inert gas). The reaction kinetics differ according to the fluorination mode [31]; static fluorination provides the non-decomposition of the carbonaceous matrix during fluorination.

The fibres exhibit the same trends than graphite regarding their reactivity towards molecular fluorine. The higher the graphitization degree, the higher the fluorination temperature [32]. When the specific surface area is increased, through a nanostructuration (e.g. nanofibres [33] or multiwalled carbon nanotubes, MWCNTs [34]), or porosity [35], the reactivity increases as well the risk of decomposition under $\mathrm{F}_{2}$ atmosphere. It is important to note the risk of exfoliation when the reactive gas is introduced at high temperature with high reactive gas flux. The case of nanofibres perfectly evidences such a phenomenon [36]. When the carbon lattice exhibits a curvature, the reactivity towards $\mathrm{F}_{2}$ increased; fullerenes and derivatives (nanotubes) may be fluorinated at low temperature and even at room temperature [37].

When only the surface must be fluorinated, reaction in fluorine-containing gas assisted by plasma is an alternative. For many years, this technique has been used in order to modify the surface properties of different materials. Indeed, if first employed for changing the surface properties (hydrophobicity, adhesion, friction, bio-compatibilization, etc.) of different polymers [38], plasmas were quickly used to treat carbon fibres during the 80's [39-41]. The main use of these fibres is polymer matrix reinforcement for the preparation of composites. Thereby, all of these treatments were aiming at preparing the surface of the fibres in order to improve the interface properties between both components of these materials. Treatment are therefore mainly devoted to cleaning the surface by removing the impurities, creating a surface roughness to improve the mechanical anchorage of the resin, or the chemical grafting on the fibre surface to create chemical interactions between the fibres and the matrix [42]. Thereby, as an example, some researchers have demonstrated that plasma treatment of carbon fibres allows the surface roughness of fibres to be increased and, consequently, enhances their adhesion with polymers [43-45]. Some others have carried out experimentations that aim at grafting chemical groups at the outmost surface of carbon fibres. Most of the time, oxygen-based plasma were carried out in order to graft oxygen groups $(\mathrm{COOH}, \mathrm{C}-\mathrm{OH}, \mathrm{C}=\mathrm{O})$ at the fibre surface, especially to improve the carbon fibres/epoxy matrix interface via the addition of these polar groups [39,46-48]. 
On the other hand, if fluorinated plasmas were first developed for micro-electronic etching [49], they were quickly employed to modify surface properties of various carbon compounds (graphite, diamond, etc.) [50,51], in order to confer to the latter ones surface properties of fluorocompounds (hydrophobicity, corrosion resistance, low dynamic friction, high scratch resistance, etc.) without modification of the bulk properties in the same way than direct fluorination. Typical used fluorinating agents are $\mathrm{SF}_{6}, \mathrm{NF}_{3}, \mathrm{CF}_{4}, \mathrm{CHF}_{3}, \mathrm{C}_{2} \mathrm{~F}_{6}, \mathrm{C}_{3} \mathrm{~F}_{6}$ and $\mathrm{C}_{4} \mathrm{~F}_{8}$ gases $[52,53]$. In the reactor, electrons which compose the plasma will acquire enough energy to initiate dissociation, ionization or attachment reactions with the molecule radicals or atoms [49], which are very effective reactions on carbon compounds. However, it is only in 1987 that Loh et al. [40] published one of the first papers on carbon fibre fluorination in plasma, using $\mathrm{CF}_{4}-\mathrm{He}$ and $\mathrm{F}_{2}-\mathrm{He}$ plasmas at various flow rates to modify the surface properties of these compounds [40]. Results demonstrated covalent grafting of fluorine atoms at the outmost surface of carbon fibres by forming a chemical structure similar to that of graphite fluoride. Thereafter, it would be necessary to wait Ho et al. works to really discover the possibilities brought by fluorination treatments in the composite field. Indeed, by using a $\mathrm{N}_{2}+$ $\mathrm{CHClF}_{2}$ gas mixture atmospheric plasma jet treatment, the authors succeeded to increase the water contact angle of fibres from $55^{\circ}$ to $103^{\circ}$ but with the appearance of pinholes on the fibres surface [54]. This modification allowed to increase the compatibility of these fibres with polyvinylidene fluoride (PVDF) matrix. Indeed, results showed that the contact angle between treated fibres and melt PVDF is reduced, interfacial shear strength is increased, and this without modifying the bulk mechanical properties of the fibres [55-57]. The interest of fluorinated plasma treatments for composite applications is well highlighted by this last example.

RT-pulsed fluorination has been developed for materials that cannot be fluorinated using direct fluorination (e.g. carbon aerogels, CA), due to their high specific surface areas or high $\mathrm{sp}^{3}$ hybridised carbon amounts, with the objective to create a fluorination method less expensive than controlled fluorination [35]. It is similar to static fluorination, although the pre-calculated amount of fluorine is not introduced at once, but in several small injections, allowing to observe the fluorine absorption and reaction kinetics, divided into 4 steps according to the authors: after vacuum and fluorine first injection (step 1), fluorine rapidly reacts with $\mathrm{CA}$, leading to a purification of the carbon lattice and fluorine grafting on the surface vacant sites of the carbon (step 2). After several injections, the fluorine absorption by CA is slower, because vacant sites become rarer (step 3), and the CA ends being saturated with fluorine, thus stopping the reaction (step 4). RT-pulsed fluorination avoids decomposition or generation of structural defects.

For both direct fluorination with $\mathrm{F}_{2}$ or assisted with plasma, the presence of heteroatoms (e.g. $\mathrm{O}, \mathrm{H}$ or $\mathrm{N}$ ) in the fluorinating agent plays a key role in the reaction mechanisms because they are involved in functional groups with high reactivity towards fluorinated species. These heteroatoms allow to reach high fluorine amounts [58-60], because the intercalation of fluorine is enhanced by the presence of Lewis acids $\left(\mathrm{O}_{2}\right.$ or HF): they balance the weak orientational polarizability of fluorine, by forming mobile anions, and allowing fluorine to intercalate into graphite as the mobile anion [59]. Moreover, the formation of C-F covalent bonds and hydroxide radicals makes the surface more basic, which hinders the fluorination reaction to go further. By acidifying the fibre surface, Lewis acids curb this basifying effect [59].

Another advantage of oxyfluorination, linked to the increased reactivity of fluorine in the presence of Lewis acids, is that treatments appear to be short with relatively low pressures and temperatures, with durations as 3-10 $\min$ [3,61-63], 30-60 $\mathrm{min}$ [64-66] or $120 \mathrm{~min}$ [59], while fluorinations under pure fluorine generally last from 15 min [67] to several hours 
$[58,60]$ or days $[60,68]$, under high temperatures for short durations. As shown by the works cited above about oxyfluorination, despite durations are short, this treatment leads to highfluorine and relatively low-oxygen surface contents.

Another promising fluorination route is the fibre sizing one. It is to note that although most commercial carbon fibres are sized, both to protect them during handling and textile processing [69] and to improve their compatibility with polymer matrices [70,71], they are often desized before fluorination $[54,67,72]$ or acquired unsized $[3,59,62,63]$. If they are fluorinated with their sizing, its influence is neglected as it burns under strong fluorination conditions $[61,67,72]$. However, under mild fluorination conditions, it is possible to achieve a sizing perfluorination, as shown on carbon [73] and flax [22] fibres. This perfluorination has conferred interesting properties, e.g. increased hydrophobicity, without modifying the fibre structure and bulk properties, as it will be studied later.

The fluorination mechanism on Bisphenol A diglycidyl ether (DGEBA) as a sizing agent has been studied in [22], where a wide variety of potential perfluorinated and overfluorinated groups derived from DGEBA have been evidenced. Knowing that i) the oxirane ring of DGEBA has an important internal tension, ii) the aromatic rings are highly reactive, and iii) the $\mathrm{C}_{6} \mathrm{~F}_{10}$ ring is stable, some fluorinated groups are more likely to form than others. Moreover, the authors have established preferential scission sites on perfluorinated DGEBA, underlining the DGEBA reactivity under fluorine treatment [22].

More generally, fluorination of polymer converts $\mathrm{CH}_{\mathrm{x}}$ groups in $\mathrm{CF}, \mathrm{CF}_{2}$ and $\mathrm{CHF}_{\mathrm{y}}$ groups [74,75], with $\mathrm{CF}_{2}$ and $\mathrm{CF}_{3}$ being characteristic of respectively perfluorination and $\mathrm{C}-\mathrm{C}$ skeleton breaking, while $\mathrm{C}=\mathrm{C}$ bonds are saturated with fluorine, as extensively proved in Kharithonov's studies on polymer fluorination [23,24,76-80].

Other fluorination routes exist, e.g. atomic and controlled fluorination or sub-fluorination. Their specificities and mechanisms will be detailed in section 3.2.2. Figure 1 summarizes the most usual routes and their main parameters. 


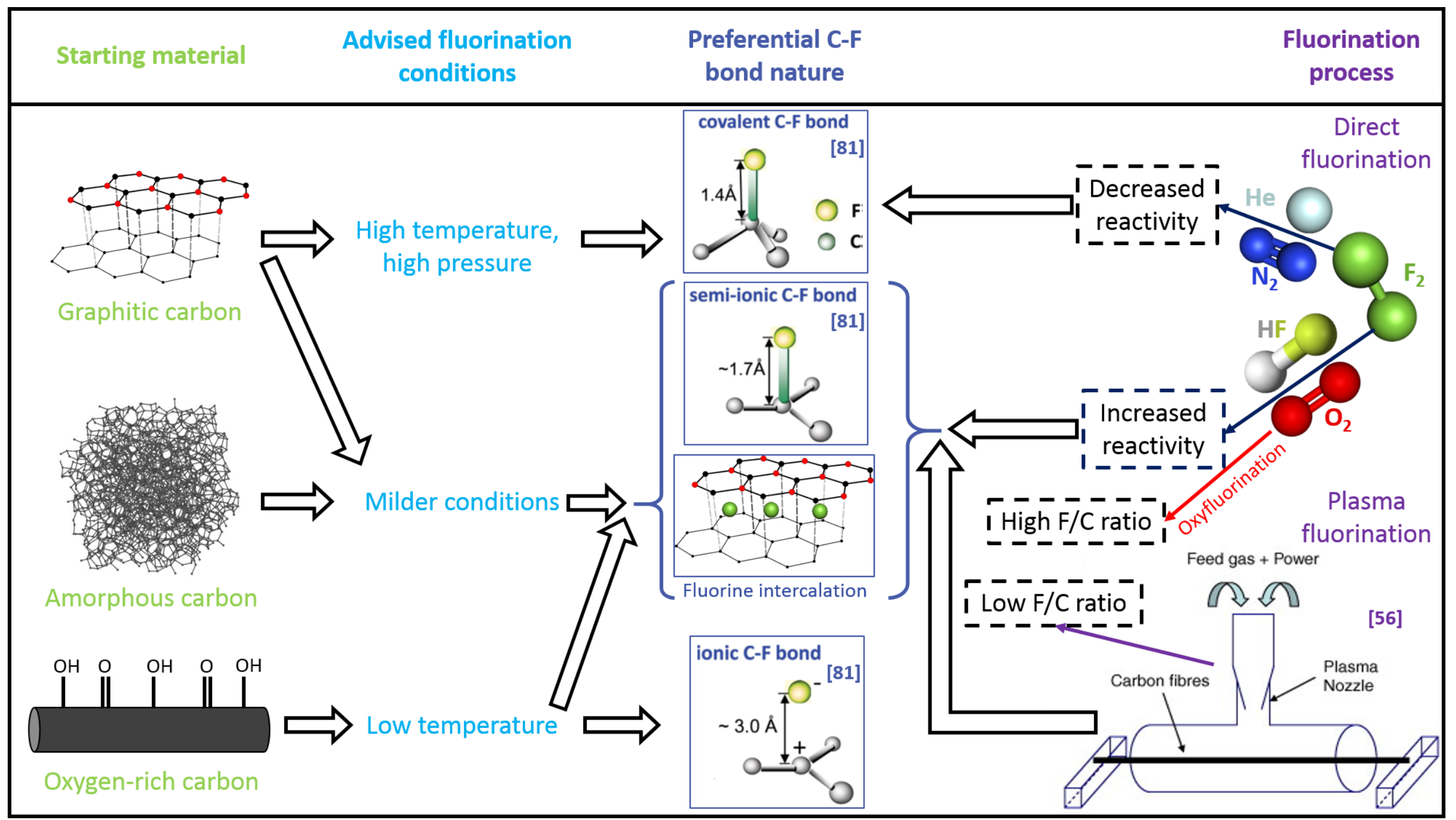

Figure 1: The fluorination routes for carbon fibres and their main parameters (some figures were reprinted from [56], with permission from Elsevier, and from [81]) 
To conclude this part about the (oxy)fluorination routes, the main experimental difficulties that can be met when fluorinating carbon fibres, beyond fluorine intrinsic hazards, are cited thereafter:

- Exfoliation, mentioned above, happens when the reactive gas is introduced at high temperature with high reactive gas flux. If high temperatures are required for reaction, it can be avoided by setting a moderate reactive gas flux.

- High gas flux may also, if fibres (or powder) are too close to the gas entry, pulverise the carbon material into the whole reactor, thus polluting it.

- Direct fluorination of carbon materials being highly exothermic, a strict control of the fluorination duration (second by second) and gas flows (accuracy deviation below 1 $\mathrm{mL} / \mathrm{min}$ ) are necessary to obtain materials with similar fluorination rates.

- Industrial carbon fibres are often commercialised as fabric rolls made of carbon fibre bundles (e.g. 12000 fibres per bundle). If the post-fluorination application needs the fibres to be long (e.g. $40 \mathrm{~cm}$ ), as bundles are poorly foldable, this means that the fluorination reactor has to be long enough to fluorinate the whole fibre length homogeneously. Moreover, if the reactor has only one gas entry, the closest portion of carbon fibre fabric might be more intensely fluorinated than the other ones, raising the question of fluorine introduction into the reactor. This problem might be solved by innovative fluorination processes, such as in [56], where the authors have achieved continuous fibre fluorination.

- Another problem, directly coming from the reactor size required for long carbon fibre fluorination, is the temperature one: if small reactors can be easily and homogeneously heated at important temperatures, with real temperature close to the setpoint one, this is more complex with voluminous reactors, which may have important offsets between real and setpoint temperatures. Before fluorination, this offset should be measured using a thermocouple. Concerning the temperature homogeneity, it can be improved by using a double envelope reactor, but still needs time to be achieved.

- Standard industrial carbon fibres are usually sized, the sizing being a thin polymeric coating. It is often an epoxy resin, for further use with epoxy matrix [82] or more specifically diglycidyl ethers, the most used matrices for composite applications [83]. If fibres are not desized before fluorination and that fluorination temperatures are low, sizing fluorination takes place [73]. Unless the latter phenomenon is sought, the fluorination temperature and/or duration should be important enough to fluorinate the carbon fibre and completely destroy the sizing.

\section{Fluorine content and bonding}

The differences in surface element content and bonding between pristine and (oxy)fluorinated carbon fibres reported in literature will be first discussed. These differences were notably highlighted thanks to elemental analysis (EA), chemical analysis (CA), weight uptake, chemical titration, and XPS analysis. The latter technique allows to know the outmost surface $(<10 \mathrm{~nm})$ composition of a sample and the bond nature of the detected elements.

\subsection{Study of the carbon fibre surface before the (oxy)fluorination treatment}

Elemental and XPS analysis processed before (oxy)fluorination give information about the initial carbon fibre surface composition. Table 1 computes the compositions reported in literature. 
Table 1: Reported compositions of carbon fibre precursors using XPS and CA

\begin{tabular}{cccccc}
\hline Reference & $\begin{array}{c}\text { C surface } \\
\text { content }(\%)\end{array}$ & $\begin{array}{c}\text { O surface } \\
\text { content }(\%)\end{array}$ & $\begin{array}{c}\text { N surface } \\
\text { content }(\%)\end{array}$ & $\begin{array}{c}\text { Si surface } \\
\text { content }(\%)\end{array}$ & O/C ratio \\
\hline$[68]$ & 100 & - & - & - & - \\
\hline$[72]$ & 95.7 & 3.4 & 0.9 & - & 0.04 \\
\hline$[58]$ & 95 & 5 & - & - & 0.05 \\
\hline$[58,59]$ & 94.5 & 3.8 & 1.7 & - & 0.04 \\
\hline$[56]$ & 90.6 & 7 & 2.4 & - & 0.08 \\
\hline$[68]$ & 89 & $\mathbf{6}$ & $\mathbf{5}$ & - & 0.07 \\
\hline$[67]$ & 88.7 & 11.3 & - & - & 0.13 \\
\hline$[3,62,63]$ & 88.4 & 9.6 & - & - & 0.11 \\
\hline$[60,68]$ & 83 & 14 & 3 & - & 0.17 \\
\hline$[67]^{1}$ & 82.1 & 2.5 & 14.1 & - & 0.03 \\
\hline$[54]$ & 75.4 & 18 & 1.2 & 5.4 & 0.24 \\
\hline$[66]$ & 55 & 45 & - & - & 0.82 \\
\hline
\end{tabular}

Overall, fibre surfaces appear to be mostly constituted of carbon. Heteroatoms like oxygen, nitrogen or silicon are sometimes present and are considered like impurities, which can amongst others come from the fibre handling [54]. One could assume that these heteroatoms could come from the sizing, but some of the fibres with the highest $\mathrm{O} / \mathrm{C}$ ratio were unsized $[3,62,63]$ or desized [54], which excludes the hypothesis with the sizing.

It is to note that the most carbonaceous surfaces, reported in [68], correspond to hightemperature treated (HTT) carbon fibres. This graphitisation at $3000^{\circ} \mathrm{C}$ has completely removed the $11 \%$ of heteroatoms (bold text in Table 1), and has only left carbon. In that respect, most of the commercially available carbon fibres studied here have an 80-96\% carbon surface content, a $2.5-14 \%$ oxygen surface content, a nitrogen surface content under $5 \%$, and an $\mathrm{O} / \mathrm{C}$ ratio under 0.20 .

It is now possible to study more precisely how the carbon atoms and heteroatoms are bonded together on the surface of non-(oxy)fluorinated fibres, thanks to XPS. This technic indeed allows to determine the nature of the surface atomic bonds, thanks to the study of the $\mathrm{C} 1 \mathrm{~s}$ and $\mathrm{O} 1 \mathrm{~s}$ binding energies and their deconvolution in several peaks, which are characteristic of a specific bonding. Table 2 and Table 3 summarize binding energies of common functional groups in the $\mathrm{C} 1 \mathrm{~s}$ and $\mathrm{O} 1 \mathrm{~s}$ areas, while Table 4 computes the calculated amounts of each bond on carbon fibre surface according to literature.

Table 2: Binding energies (eV) of $\mathrm{C} 1 \mathrm{~s}$ atomic bonds commonly found at carbon fibre surface

\begin{tabular}{|c|c|c|c|c|c|c|}
\hline Reference & [84] & [85] & {$[86]$} & {$[87]$} & {$[88]$} & [89] \\
\hline $\mathrm{C}=\mathrm{C}$ & 284.5 & - & 284.2 & 285.2 & \multirow{2}{*}{284.5} & - \\
\hline $\mathrm{C}-\mathrm{C}$ & - & 284.5 & 284.9 & 284.6 & & 285 \\
\hline $\mathrm{COH}$ & \multirow{2}{*}{286.0} & \multirow{2}{*}{285.9} & 285.5 & \multirow{2}{*}{286.7} & 285.6 & 286.6 \\
\hline $\mathrm{COC}$ & & & 286.4 & & - & \\
\hline $\mathrm{C}=\mathrm{O}$ & 287.4 & 287.3 & 287.7 & - & 288.2 & 288.1 \\
\hline
\end{tabular}

\footnotetext{
${ }^{1}$ Values determined by CA
} 
Table 3: Binding energies (eV) of $\mathrm{O} 1 \mathrm{~s}$ atomic bonds commonly found at carbon fibre surface

\begin{tabular}{cccccc}
\hline Reference & {$[84]$} & {$[90]$} & {$[91,92]$} & {$[93]$} & {$[94]$} \\
\cline { 1 - 5 } $\mathrm{C}=\mathrm{O}$ & 531.1 & 532.2 & 532.3 & 532.6 & 530.9 \\
\cline { 1 - 5 } $\mathrm{C}-\mathrm{O}$ & 533.1 & 532.8 & 533.8 & 534.3 & - \\
\cline { 1 - 5 } $\mathrm{O}=\mathrm{C}-\mathrm{O}$ & \multirow{2}{*}{534.0} & 532.2 & - & - & \multirow{2}{*}{532} \\
\cline { 1 - 4 } $\mathrm{O}=\mathrm{C}-\mathrm{O}-\mathrm{C}$ & & 533.7 & - & - & \\
\hline
\end{tabular}

Then, the XPS spectra are deconvoluted in several peaks according to these values. The comparison between the peak areas allows the amount of each type of bond to be estimated (Table 4).

Table 4: Reported relative contents (\%) of various assignments for $\mathrm{C} 1 \mathrm{~s}$ and $\mathrm{O}$ 1s cores using XPS on carbon fibre precursors

\begin{tabular}{cccccccccccc}
\hline & Reference & {$[58,68]$} & {$[59]$} & {$[58]$} & {$[68]$} & {$[60,68]$} & {$[66]$} & {$[67]$} & {$[67]$} & {$[64]$} & {$[64,65]$} \\
\hline $\mathrm{C} 1 \mathrm{~s}$ & Graphitic C (\%) & 100 & 77.8 & 86.8 & 70 & 67 & 55 & 48.1 & 42.3 & 42 & 40 \\
\hline $\mathrm{COC} \mathrm{COH} \mathrm{( \% )}$ & - & 11.8 & 13.2 & 21 & 33 & 25 & 44.1 & 38.8 & 34 & 16 \\
\hline $\mathrm{C}=\mathrm{O}(\%)$ & - & 10.4 & - & 9 & - & 20 & 7.9 & 18 & 24 & 31 \\
\hline $\mathrm{O}-\mathrm{C}=\mathrm{O}(\%)$ & - & - & - & - & - & - & - & - & - & 13 \\
\hline & Undefined (\%) & - & - & - & - & - & - & - & 0.9 & - & - \\
\hline $\mathrm{O} 1 \mathrm{~s}$ & $\mathrm{C}=\mathrm{O}(\%)$ & - & - & - & - & - & 54 & - & - & - & 45 \\
\hline $\mathrm{CO}(\%)$ & - & - & - & - & - & 46 & - & - & - & 29 \\
\hline & $\mathrm{O}-\mathrm{C}=\mathrm{O}(\%)$ & - & - & - & - & - & - & - & - & - & 26 \\
\hline
\end{tabular}

The reported relative contents greatly differ depending on the study, but all fibre surfaces appear to be mainly constituted of graphitic carbon, and of ether, hydroxyl, carbonyl, and carboxyl groups. It is of primary importance to know more about the carbon fibres before their treatment because fluorination will focus preferentially on oxygenated groups [67] and $\mathrm{sp}^{2}$ carbons [95].

\subsection{Study of the (oxy)fluorinated carbon fibre surface}

\subsubsection{Surface atomic contents}

As Table 1 and Table 4 have given an overview about the surface composition of the carbon fibre precursors, a compilation has been done on fluorinated and oxyfluorinated carbon fibres. For the surface atomic contents, this leads to Figure 2 and

Table 5, where APF stands for "Atmospheric Plasma Fluorination".

\footnotetext{
${ }^{2}$ For $[60,68], \mathrm{C}=\mathrm{N}$ is also included in this $\%$
} 


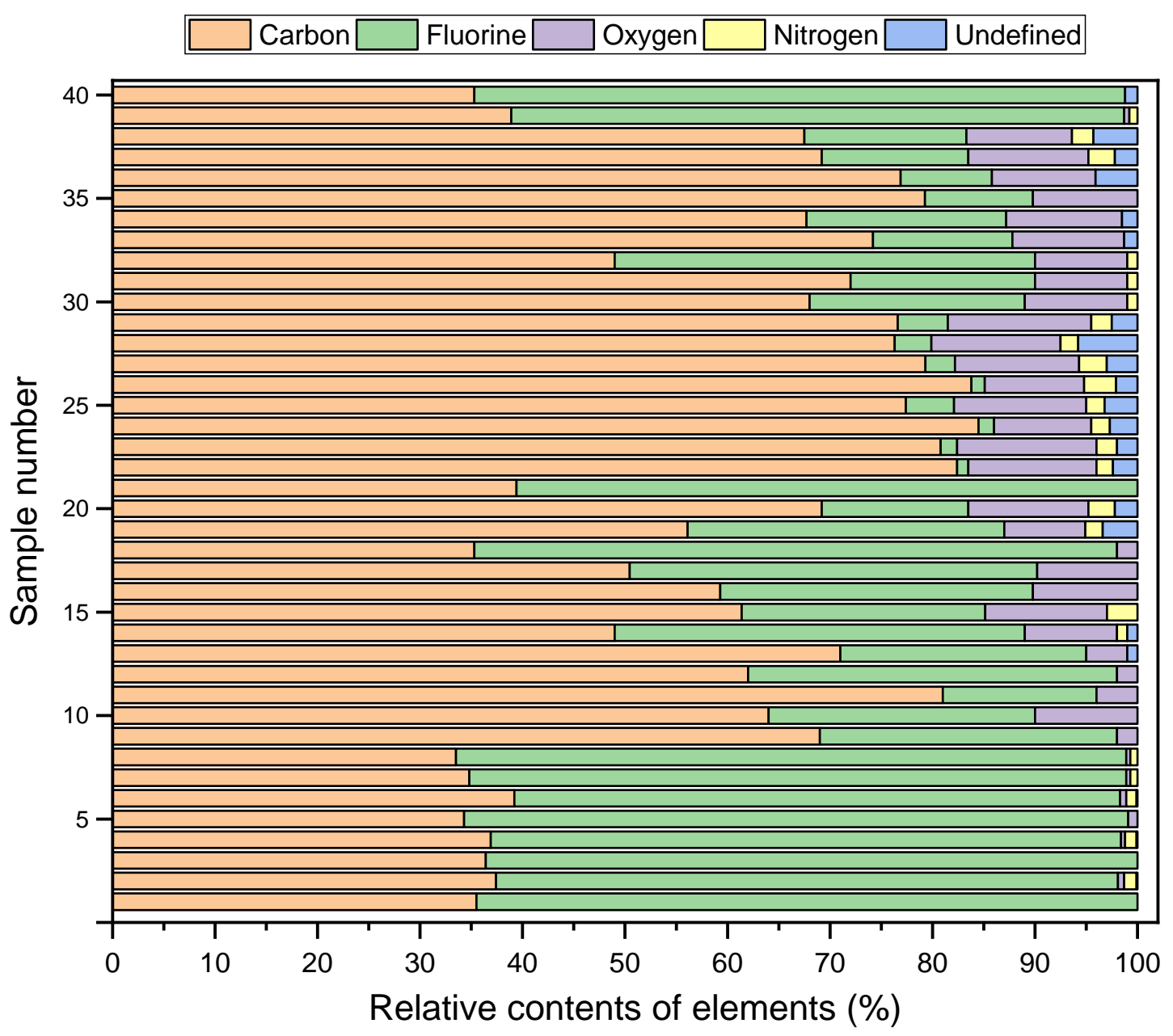

Figure 2: Relative surface atomic contents of fluorinated carbon fibres according to literature, using XPS and EA

Table 5: Correspondence between the sample numbers of Figure 2 and the way samples are referred in literature

\begin{tabular}{|c|c|c|c|c|c|c|c|}
\hline Sample & Reference & Sample & Reference & Sample & Reference & Sample & Reference \\
\hline 1 & [67] T300B & 11 & $\begin{array}{c}\text { [68] HTT } 1 \\
\text { P55 ST3 }\end{array}$ & 21 & [58] T2 & 31 & {$[60] n^{\circ} 3$} \\
\hline 2 & [67] T300C & 12 & $\begin{array}{c}\text { [68] HTT 1 } \\
\text { IPCL } \\
\text { ST1+ST2 }\end{array}$ & 22 & $\begin{array}{c}\text { [54] } 1 \mathrm{~min} \\
\text { APF }\end{array}$ & 32 & {$[60] n^{\circ} 4$} \\
\hline 3 & $\begin{array}{c}{[67]} \\
\text { T300D }\end{array}$ & 13 & $\begin{array}{c}68] \text { HTT 1 } \\
\text { NPL } \\
\text { ST1+ST2 }\end{array}$ & 23 & $\begin{array}{c}\text { [54] } 4 \text { min } \\
\text { APF }\end{array}$ & 33 & $\begin{array}{l}{[3,62,63]} \\
\text { CFO-RT }\end{array}$ \\
\hline 4 & [67] T300E & 14 & [68] IPCL & 24 & $\begin{array}{c}\text { [54] } 8 \text { min } \\
\text { APF }\end{array}$ & 34 & $\begin{array}{l}{[3,62,63]} \\
\text { CFO-100 }\end{array}$ \\
\hline 5 & [67] T700B & 15 & [68] NPL & 25 & [56] Batch & 35 & $\begin{array}{l}{[3,62,63]} \\
\text { CFO-300 }\end{array}$ \\
\hline 6 & [67] T700C & 16 & [58] C1 & 26 & $\begin{array}{c}\text { [56] } \\
\text { Continuous } \\
\text { single sided }\end{array}$ & 36 & $\begin{array}{l}{[3,62,63]} \\
\text { CFO-400 }\end{array}$ \\
\hline
\end{tabular}




\begin{tabular}{|c|c|c|c|c|c|c|c|}
\hline 7 & $\begin{array}{c}{[67]} \\
\text { T700D }\end{array}$ & 17 & [58] C2 & 27 & $\begin{array}{c}56] \\
\text { Continuous } \\
\text { double } \\
\text { sided } 1 \\
\end{array}$ & 37 & [59] CF-20 \\
\hline 8 & [67] T700E & 18 & [58] C3 & 28 & $\begin{array}{c}{[56]} \\
\text { Continuous } \\
\text { double } \\
\text { sided } 2 \\
\end{array}$ & 38 & $\begin{array}{l}\text { [59] CF- } \\
125\end{array}$ \\
\hline 9 & $\begin{array}{c}\text { [68] HTT } 1 \\
\text { P75 ST1 }\end{array}$ & 19 & [58] C4 & 29 & $\begin{array}{c}56] \\
\text { Continuous } \\
\text { double } \\
\text { sided } 3 \\
\end{array}$ & 39 & $\begin{array}{c}\text { [59] CFO- } \\
20\end{array}$ \\
\hline 10 & $\begin{array}{c}68] \text { HTT } 1 \\
\text { P55 } \\
\text { ST1+ST2 }\end{array}$ & 20 & [58] T1 & 30 & {$[60] n^{\circ} 2$} & 40 & $\begin{array}{c}\text { [59] CFO- } \\
125\end{array}$ \\
\hline
\end{tabular}

As it can be seen on Figure 2, the surface composition of carbon fibres is highly disparate, even from one sample to another within the same study. The surfaces are mostly constituted of carbon and fluorine: the minimum surface content of \{carbon + fluorine $\}$ is $80 \%$ and is reached on fibres moving through a fluorinated atmospheric plasma (sample $\mathrm{n}^{\circ} 28$ in Figure 2). The fluorine content range is large, from 1.1-1.6\% up to 55-65\%, depending on the fluorination treatment.

On one hand, atmospheric plasma fluorination leads to the lowest fluorine grafting (1.1-1.6\%) [54]. A $\mathrm{CHClF}_{2}-\mathrm{N}_{2}$ mixture has been used to generate a plasma that fluorinates fibres for various durations ( 1 to $8 \mathrm{~min}$ ). Even if the fluorine content is low, it can be noted that APF is intense enough to decrease the surface content of heteroatoms. Another study [56] using the APF of carbon fibres, with the same gas mixture, has led to surface fluorine amounts from $1.3 \%$ up to $4.9 \%$ : these amounts are slightly higher than in [54] and the chosen method offers an interesting processing advantage, as the fibres to be treated are not static anymore but moving through the plasma jet in a continuous process. But in both cases, it is to note that these contents remain low compared to the ones reached with more severe fluorination treatments.

On the other hand, the highest fluorine contents (55-65\%) were reached in [67], by using direct fluorination with molecular fluorine $F_{2}$ (samples $n^{\circ} 1-8$ in Figure 2). The main parameter resulting in these fluorine contents appears to be the temperature. As a matter of fact, this study has involved the highest reported temperatures, i.e. $378^{\circ} \mathrm{C}$, to the best of our knowledge, and it has led to the highest fluorine surface contents.

Other studies have reported samples with high fluorine amounts [58-60]. All of these samples $\left(\mathrm{n}^{\circ} 18,21,32,39\right.$ and 40 of Figure 2$)$ have a common characteristic: the reacting gas is not pure fluorine, but rather a $\mathrm{F}_{2}-\mathrm{HF}$ or $\mathrm{F}_{2}-\mathrm{O}_{2}$ mixture, which has been explained in 2 . The importance of Lewis acids is highlighted by the fluorine content gap between samples $\mathrm{n}^{\circ} 37$ $38\left(\mathrm{~F}_{2}\right.$ fluorination $)$ and $\mathrm{n}^{\circ} 38-39\left(\mathrm{~F}_{2}-\mathrm{O}_{2}\right.$ oxyfluorination $)$ of Figure 2: the first ones have 14$16 \%$ surface fluorine contents, while the second ones exhibit $60-65 \%$ surface fluorine contents [59].

The treatment duration also seems responsible for an increase of the fluorine surface content. This is highlighted by the fact that sample ${ }^{\circ} 32$ in Figure 2, which has been fluorinated for 9 days, has a higher fluorine surface content (41\%) than samples $n^{\circ} 30$ and $n^{\circ} 31(18-21 \%)$, 
which have been fluorinated for respectively 1 and 5 hours, with almost the same gaseous mixture and same pressure [60].

As we consider a heterogeneous gas/solid reaction, another parameter that could increase the fluorine surface amount is pressure, as highlighted by sample $n^{\circ} 17$ in Figure 2, which is the only high-fluorinated sample and has not been fluorinated with a Lewis acid. Two factors could then explain this high fluorine amount despite a pure $\mathrm{F}_{2}$ fluorination: first, the fluorination of this sample has lasted for 6 hours. As seen just above, this could enhance the grafting of fluorine on the carbon fibre surface. Secondly, this sample has been fluorinated under high pressure (21-26 bars), which could increase the proportion of fluorine grafted.

To briefly talk about other chemical species at the surface of (oxy)fluorinated fibres, there are traces of nitrogen, from $0 \%$ up to $3.1 \%$ on sample $n^{\circ} 26$ of Figure 2 (continuous APF fibres). About oxygen, it can be found in various amounts, from $0 \%$ on sample $n^{\circ} 40\left(125^{\circ} \mathrm{C}\right.$ oxyfluorination) up to $13.6 \%$ on sample $\mathrm{n}^{\circ} 23$ (4 min APF fibres), according to Figure 2 . It should be noted that oxyfluorination treatments are not especially leading to rich-oxygen surfaces, as the oxyfluorinations reported in Figure 2 lead to oxygen surface amounts from 0 $0.5 \%$ (samples $n^{\circ} 39-40,[59]$ ) up to $10.1-11.3 \%$ (samples $n^{\circ} 33-36,[3,62,63]$ ).

\subsubsection{C-F bonding at the carbon fibre surface and fluorination mechanisms}

Now that the species present at the carbon fibre surface and their amounts have been specified, it is possible to discuss the nature of the chemical bonds between these atoms. To this end, XPS data from several studies have been summarized in Figure 3 and Table 6. Figure 4 and Table 7 gather XPS data that could not be included in Figure 3, because XPS peaks have been deconvoluted independently of each other.

But before studying the nature of these chemical bonds, the ways fluorine can graft to carbon will be briefly presented, in order to better understand the computed data.

First, fluorine can covalently bond to carbon, by breaking the double bonds of graphitic carbons and the conversion of carbon hybridization from $\mathrm{sp}^{2}$ to $\mathrm{sp}^{3}$. This evolution from graphitic to tetravalent carbons with the fluorination treatment has already been reported many times in various studies on fluorinated carbon fibres $[58,59,62,67,96]$, or more widely on fluorinated carbonaceous (nano)materials [95,97-101]. For ordered carbons, this $\mathrm{sp}^{2}$ to $\mathrm{sp}^{3}$ conversion occurs under pure fluorine at high temperatures (process known as "direct fluorination"), at least $300^{\circ} \mathrm{C}$ [96], or more generally under strong fluorination conditions $[58,61] .(\mathrm{CF})_{\mathrm{n}}$ and $\left(\mathrm{C}_{2} \mathrm{~F}\right)_{\mathrm{n}}$ structural types may be formed according to the temperature and duration. $\left(\mathrm{C}_{2} \mathrm{~F}\right)_{\mathrm{n}}$ with $\mathrm{FCCF} / \mathrm{FCCF}$ stacking sequence is an intermediate phase in the 350$500^{\circ} \mathrm{C}$ range whereas $(\mathrm{CF})_{\mathrm{n}}(\mathrm{FCF} / \mathrm{FCF}$ stacking) is formed at the highest temperatures up to $650^{\circ} \mathrm{C}[102]$ : the higher the temperature, the higher the fluorination level $x(x=\mathrm{F}: \mathrm{C}, 0.5<x<$ 1) $[103]$.

Another point of view consists to consider graphite fluorides as covalent graphite intercalation compounds with stage 1 and 2 for $(\mathrm{CF})_{\mathrm{n}}$ and $\left(\mathrm{C}_{2} \mathrm{~F}\right)_{\mathrm{n}}$, respectively. Purely covalent C-F bonds are then formed and are stable up to $500^{\circ} \mathrm{C}$ [96]. These covalent bonds are evidenced with XPS, through a peak at $689 \mathrm{eV}$ [67].

Another possible kind of bonding between fluorine and carbon that can be observed through XPS is the intercalation of fluorine into the graphitic structure. It has been reported to occur at quite low temperatures $\left(<100^{\circ} \mathrm{C}\right)[62,96]$, when the gaseous mixture is composed of fluorine and fluorides, such as $\mathrm{HF}, \mathrm{ClF}_{3}$ or $\mathrm{IF}_{5}[59,62,96,103]$. When fluorination takes place with $\mathrm{F}_{2}$, $\mathrm{HF}$ and another fluoride, it is described as "catalysed fluorination". In this case, Guérin et al. 
have highlighted that the fluoride choice influences the fluorination level, the latter one being related to the Lewis acidity of the fluoride and its interaction with HF [103]. They have also studied the post-fluorination mechanism of low temperature fluorinated graphite depending on the post-fluorination temperature: fluorine bonding can be weakly covalent with residual catalyst $\left(\mathrm{T}<400^{\circ} \mathrm{C}\right)$, increasingly covalent thanks to catalyst de-intercalation and fluorine amount increase $\left(400^{\circ} \mathrm{C}<\mathrm{T}<550^{\circ} \mathrm{C}\right)$, or totally covalent, with less structural defects than directly-fluorinated graphite $\left(550^{\circ} \mathrm{C}<\mathrm{T}<680^{\circ} \mathrm{C}\right)$.

Intercalation happens because the reaction between pure fluorine and carbon is kinetically limited at low temperatures: fluorine reacts with the surface carbon to form covalent C-F bonds, and prevents the fluorine progression deeper in the fibre bulk, and thus further fluorination [59]. In this case of intercalation, the $\mathrm{sp}^{2}$ state of carbon, i.e. the planarity of graphene layers, is maintained: the fluorine only inserts into the graphitic structure as a graphite intercalation compound (GIC) and is linked to carbon through ionic $(x<0.25)$ or semi-covalent $(0.25<x<0.5)$ bonds, i.e. with weakened covalence. GICs have the general formula $\mathrm{C}_{\mathrm{x}} \mathrm{F}$, where $1.3<\mathrm{x}<20$, and are unstable, even at low temperatures $[59,62,96]$. It has been reported that the more the fibres were graphitised, the more it was possible to intercalate fluorine in the layered pattern $[61,68]$. Another source for weakening of the covalence for C-F is the dilution of $\mathrm{C}-\mathrm{F}$ bonds that results in neighbouring of $\mathrm{C}-\mathrm{F}$ bonds with non-fluorinated $\mathrm{sp}^{2}$ $\mathrm{C}$ atoms; an hyperconjugation takes place as proposed by Sato et al. [104].

In the case where perfluorinated groups $\left(\mathrm{CF}_{2}, \mathrm{CF}_{3}\right)$ are unwanted, fluorination can be done by using atomic fluorine $\mathrm{F}^{\bullet}$ rather than molecular fluorine $\mathrm{F}_{2}$, thus favouring formation of $\mathrm{C}-\mathrm{F}$ bonds [103]. This process, called "sub-fluorination" or "controlled fluorination", can be achieved by thermal decomposition of a fluorinated compound called "fluorinating agent" (FA), e.g. $\mathrm{XeF}_{2}$ or $\mathrm{TbF}_{4}$, which will release a controlled amount of atomic fluorine into the reactor. The recombination of two $\mathrm{F}^{\bullet}$ in $\mathrm{F}_{2}$ is avoided because the reaction between carbon and $\mathrm{F}^{\bullet}$ is spontaneous [105]. Fluorination, whose kinetics depends on the FA decomposition rate [105], is then more progressive, less aggressive and homogenous, and leads to $(\mathrm{CF})_{\mathrm{n}}$-type phase, i.e. highly-fluorinated phase, whatever the fluorination conditions. Few $\left(\mathrm{C}_{2} \mathrm{~F}\right)_{\mathrm{n}}$ phase, $\mathrm{CF}_{2}$ and $\mathrm{CF}_{3}$ groups or dangling bonds are formed [103], while decomposition by overfluorination is avoided [105].

Fluorination mechanisms have also been studied at a microscopic level, notably by using Density Functional Theory (DFT) calculations on HF-catalysed fluorinated CNTs [106]. It has been found that non-regioselective $(1,2)$ equatorial and $(1,4)$ axial additions were thermodynamically favoured for flat multi-layered carbon materials, such as graphene, while curved materials such as CNT or locally-buckled graphene were rather fluorinated through $(1,4)$ addition for low temperatures. For these materials, higher fluorination temperatures result in to the migration of the fluorine atom to the $(1,4)$ to the $(1,2)$ position thanks to the formation of a hydrogen bond with the catalyst HF. These additions lead to the emergence of a pattern of fluorinated bands [105] constituted of $\mathrm{C}_{4} \mathrm{~F}$ or $\mathrm{C}_{2} \mathrm{~F}$ [106]. Zhang et al. [105] have shown that HF deposition in a pristine zone close to a fluorinated area will lead to its chemisorption with $\mathrm{H}$ atom facing a surface fluorine atom, while a HF molecule deposited in a non-fluorinated area will sit vertically above a carbon atom, the hydrogen atom being closer to the tube and will only be physisorpted, thus having a short lifetime: this explains why $\mathrm{F}_{2}$, which is catalysed by HF, is deposited near from the pre-existing fluorinated areas.

It is to note that the fluorination mechanism of graphite, previously studied, differs from the one of graphene and CNTs because fluorine can access to both sides of the carbon layer [106]. 
Concerning controlled fluorination, DFT calculations have shown that fluorine distribution at SWCNT surface is controlled by electronic repulsion between incoming fluorine atoms and carbon-bonded ones, thus explaining the controlled fluorinated homogeneity [105]. On the other hand, still using DFT, $\mathrm{F}_{2}$ fluorination of SWCNTs has led to the formation of fluorine bands separated by pristine carbon parts by armchair axial addition of fluorine atoms [107], highlighting the higher homogeneity of controlled fluorination over direct fluorination.

In all cases (covalent bonding of $(\mathrm{CF})_{\mathrm{n}}$ and $\left(\mathrm{C}_{2} \mathrm{~F}\right)_{\mathrm{n}}$, hyperconjugation or formation of GICs, or $(1,2)$ and $(1,4)$ additions), the fluorine grafting on the surface of carbon materials drastically modifies some of their properties, such as tensile strength, interfacial and structural properties $[58,59]$, as this will be discussed thereafter.

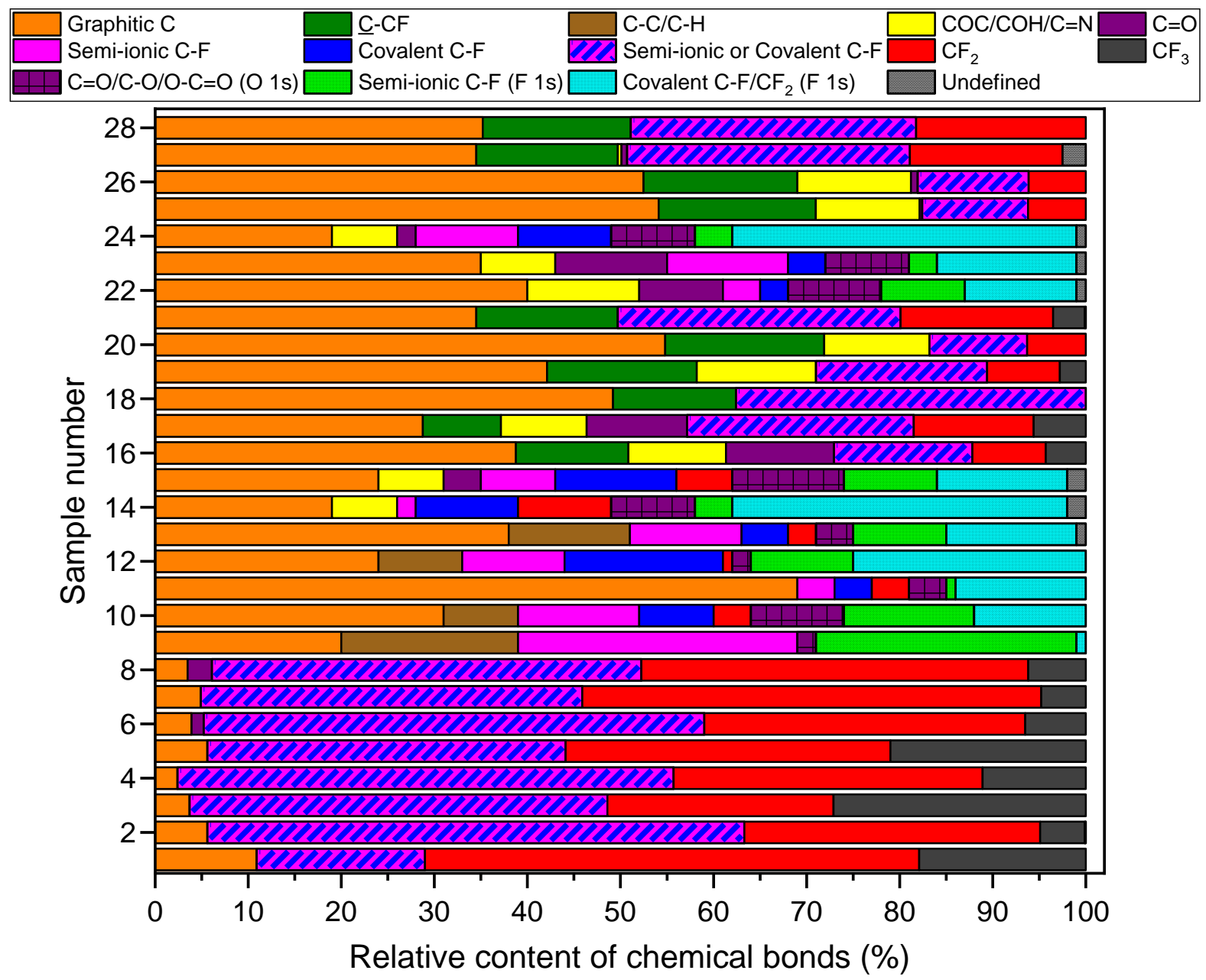

Figure 3: Relative contents of the various carbon atoms according to the bond or group where they are involved at the surface of fluorinated carbon fibres using XPS 
Table 6: Correspondence between the sample numbers of Figure 3 and the fluorination conditions used

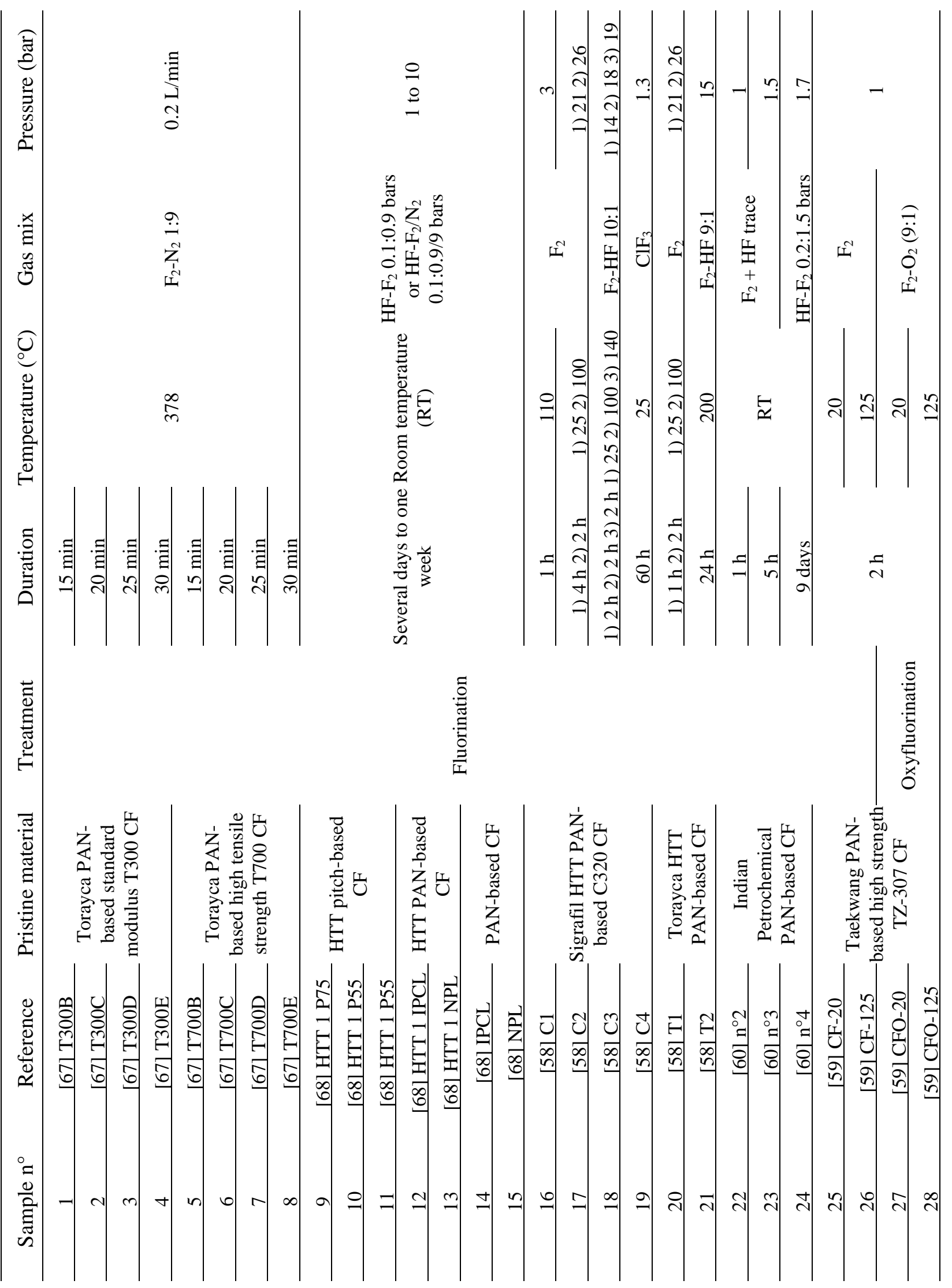




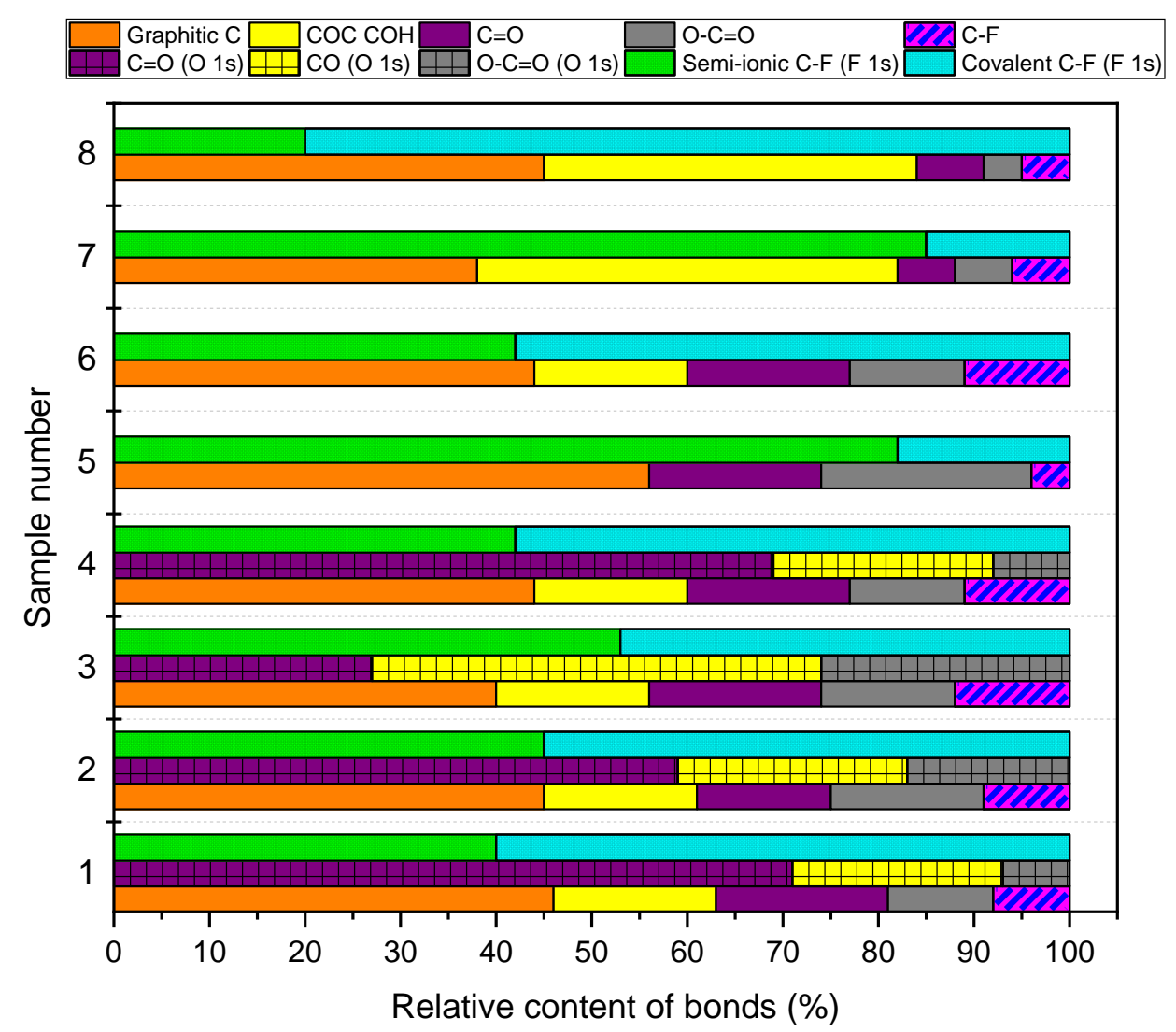

Figure 4: Relative content of the various carbon atoms according to the bond or group where they are involved at the surface of oxyfluorinated carbon fibres using XPS

Table 7: Correspondence between the sample numbers of Figure 4, their notation and the reactive gaseous mixture

\begin{tabular}{ccccccccc}
\hline Sample & 1 & 2 & 3 & 4 & 5 & 6 & 7 & 8 \\
\hline \multirow{3}{*}{ Reference } & {$[65] \mathrm{F}_{2}: \mathrm{O}_{2}$} & {$[65]$} & {$[65]$} & {$[65] \mathrm{F}_{2}: \mathrm{O}_{2}$} & {$[64]$} & {$[64]$} & {$[64]$} & {$[64]$} \\
& $1: 9 ;[64]$ & $\mathrm{F}_{2}: \mathrm{O}_{2}$ & $\mathrm{~F}_{2}: \mathrm{O}_{2}$ & $9: 1 ;[64]$ & CFO-4 ; & CFO-5; \\
& $\mathrm{CFO}-1$ & $3: 7$ & $5: 5$ & CFO-6 & CFO-2 & CFO-3 & [66] S3 & {$[66] \mathrm{S} 4$} \\
\hline
\end{tabular}

In Figure 3, the samples $n^{\circ} 1-8$ stand out from the other ones, notably because of the homogeneity of the formed chemical bonds between the samples. Fluorine is highly present at the surface of these samples, as at least $89 \%$ of the surface carbons are bonded to fluorine, through semi-covalent or covalent $\mathrm{C}-\mathrm{F}$ bonds, or involved in $\mathrm{CF}_{2}$ or $\mathrm{CF}_{3}$ groups. The remaining carbons are mainly involved in $\mathrm{C}=\mathrm{C}$ graphitic bonds, which is the main kind of bonds in non-fluorinated carbon fibres, as seen in Table 4. For these samples, considering the low relative content of remaining graphitic carbons, one could think that covalent grafting has been the main fluorination mechanism.

Still discussing about these samples, it can be outlined that the high content of $\mathrm{CF}_{3}$ groups is the last stage of fluorination before the formation of gaseous species $\mathrm{CF}_{4}$ and $\mathrm{C}_{2} \mathrm{~F}_{6}$, which can lead to the removal of carbons by decomposition (combustion). This high amount of $\mathrm{CF}_{3}$ groups highlights the fact that two antagonist mechanisms are competing during the fluorination treatment: the first one leads to the desired fluorination of the surface, while the 
other one is the formation of the gaseous species cited above [67,72]. Temperature thus favours fluorination reaction, which can even lead to a degradation of the carbon fibre surface by forming $\mathrm{CF}_{3}, \mathrm{CF}_{4}$ and $\mathrm{C}_{2} \mathrm{~F}_{6}$ and partial exfoliation as discussed in section 2 . Both decomposition and partial exfoliation may increase the roughness and even the porosity. This observation has already been made $[58,59]$, and is strengthened by the fact that it has been proved that temperature was increasing the fluorination rate of polymer surfaces $[23,24,76,79,80]$ : one could consider that a similar approach can be made on carbonaceous surfaces.

Another interesting point can be raised by observing the $\mathrm{F} 1 \mathrm{~s}$ analysis provided by the different studies where fibres have been fluorinated (Figure 3): except for samples $n^{\circ} 9-10$, it can be noted than fluorine is more likely to form covalent $\mathrm{C}-\mathrm{F}$ or $\mathrm{CF}_{2}$ bonds than semi-ionic $\mathrm{C}-\mathrm{F}$ bonds. This trend is observed on samples $\mathrm{n}^{\circ} 11-15$ and $\mathrm{n}^{\circ} 22-24$, despite the set of experimental conditions reported in Table 6 (low temperatures, gas mixes containing fluorides) that could let think that semi-covalent GICs would be preferentially formed than C$\mathrm{F}$ and $\mathrm{CF}_{2}$ covalent bonds.

However, for oxyfluorinated fibres (samples $n^{\circ} 1-8$ of Figure 4), this statement is not valid anymore: depending on the sample, the proportions of semi-covalent and covalent $\mathrm{C}-\mathrm{F}$ bonds can be similar (e.g. samples $n^{\circ} 2-3$ ), or one type of bonding can be significantly more represented than the other one (e.g. samples ${ }^{\circ} 7-8$ ). Based on samples $n^{\circ} 5-7$ of Figure 4 , it can be noted that an oxyfluorination duration of $30 \mathrm{~min}$ appears to be the most efficient time to covalently graft fluorine to the carbon fibres, as $10 \mathrm{~min}$ and $60 \mathrm{~min}$ durations lead to high amounts of semi-covalently bonded fluorine. Pressure also seems to increase the proportion of covalent fluorine: sample $\mathrm{n}^{\circ} 8$ of Figure 4 has a slightly higher proportion of covalent $\mathrm{C}-\mathrm{F}$ bonds than sample $n^{\circ} 6$, and the only difference between them is the $\mathrm{F}_{2} / \mathrm{O}_{2}$ pressure. Sample $\mathrm{n}^{\circ} 8$ has indeed been oxyfluorinated at $80 \mathrm{kPa}$, while $\mathrm{n}^{\circ} 6$ has been fluorinated at $5 \mathrm{kPa}$ [64].

Figure 4 delivers an interesting information about the way oxygen atoms are bonded at the carbon fibre surface, and can be related to the oxyfluorination mechanism proposed in [59], which is reminded in Figure 5. Indeed, according to this mechanism, if fluorine and oxygen are introduced in similar amounts, all carbon radicals created by the attack of fluorine should become peroxide radicals thanks to oxygen, leading to high amounts of $\mathrm{C}-\mathrm{O}$ and $\mathrm{O}-\mathrm{H}$ bonds, detectable with XPS. This could explain why sample $n^{\circ} 3$ of Figure 4 has the highest amount of $\mathrm{C}-\mathrm{O} / \mathrm{O}-\mathrm{H}$ bonds in its $\mathrm{O} 1 \mathrm{~s}$ peak, as this sample has been oxyfluorinated with a 50/50 vol. $\% \mathrm{~F}_{2} / \mathrm{O}_{2}$ mixture [65]. 


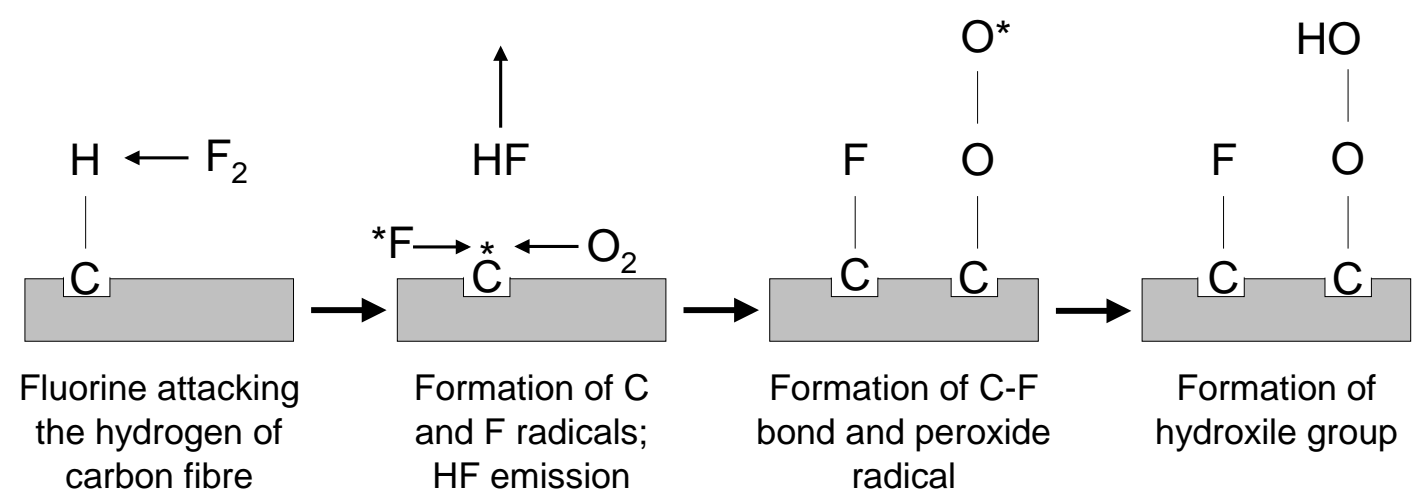

Figure 5: A suggested mechanism of direct oxyfluorination of carbon fibres, adapted from [59], with permission from Elsevier

When fluorine is introduced in higher quantity than oxygen, one could think that oxygen would not be able to bond to all the carbon radicals created with fluorine. This could lead to a fibre with a high number of free radicals, which could recombine in carbonyl bonds during exposure to $\mathrm{H}_{2} \mathrm{O}$ from ambient air; a high relative content of oxygen atoms implied in carbonyl bonds is then expected. This hypothesis could explain the high amount of $\mathrm{C}=\mathrm{O}$ bonds detected in the $\mathrm{O} 1 \mathrm{~s}$ peak in sample $\mathrm{n}^{\circ} 4$ of Figure 4, which has been oxyfluorinated with a $90 \% / 10 \% \mathrm{~F}_{2} / \mathrm{O}_{2}$ mix [65]. The effect of radicals is thus of primary importance when the (oxy)fluorination is limited close to the surface.

On the other hand, when the oxygen represents the major part of the $\mathrm{F}_{2} / \mathrm{O}_{2}$ mixture, and as oxygen oxidation has been reported to introduce many carbonyls at the surface of carbon fibres [108], one could expect a high proportion of surface oxygen atoms implied in $\mathrm{C}=\mathrm{O}$ groups; the higher the oxygen content of the gas mixture, the higher the relative content of such groups. This could explain the high amount of carbonyl functionalities of samples $\mathrm{n}^{\circ} 1-2$ of Figure 4, which have been oxyfluorinated using respectively a 10\%/90\% and a $30 \% / 70 \%$ $\mathrm{F}_{2} / \mathrm{N}_{2}$ mix [65].

In conclusion of this section about the chemical composition on and close to the surface according to XPS data about (oxy)fluorinated carbon fibres, it has been highlighted that the pressure, the temperature and the nature of the gaseous mixture result in different chemical bonds, functional groups and fluorine content that act on surface properties. Two bonding mechanisms of fluorine may exist: covalent bonding under pure fluorine at high temperature, or formation of semi-covalent GICs in presence of gaseous fluoride, at relatively low temperatures $\left(<100^{\circ} \mathrm{C}\right)$. Dilution of $\mathrm{F}$ atoms results also in weakened covalence.

\section{Morphological and surface properties induced by fluorination}

\subsection{Diameter evolution}

Studying the evolution of diameter is useful as it can give information about the (oxy)fluorination mechanisms. Slight decreases of the fibre diameter with (oxy)fluorination have already been reported, and attributed to both the partial etching of the fibres by fluorine and the formation of gaseous fluorocarbons $[60,66]$. Presence of amorphous parts on the surface may favour such an etching because of their higher reactivity towards fluorine in comparison with graphitized areas, as reported on nanofibres [33].

On the other hand, increase of the diameter has also been observed, and imputed to the diffusion of the fluorinating agent into the bulk of the fibre $[67,109]$. The interlayer distance is 
much higher in $(C F)_{n}(0.6 \mathrm{~nm})$ and $\left(\mathrm{C}_{2} \mathrm{~F}\right)_{\mathrm{n}}(0.9 \mathrm{~nm})[110,111]$ than in graphitized carbons (about $0.34 \mathrm{~nm}$ ) [112]. When both mechanisms occur, it has been highlighted than the decrease of diameter happens before the swelling [60].

\subsection{SEM observations and specific surface area (SSA)}

Like in the case of the diameter evolution where two physical phenomena occur, two opposite observations can be made on the surface of (oxy)fluorinated fibres using scanning electron microscopy (SEM). First, (oxy)fluorination can smooth the fibre surface, by attenuating the fibre striations [54,59]. (Oxy)fluorination can also roughen and damage the fibre surface, by removing weak-bonded surface layers of carbon $[54,61,67]$. Porous areas along the fibre axis have also been evidenced [61], as well as more pronounced striations and holes at the fibre surface [54,61]. Under APF, carbon sputtering has been reported too [54].

When (oxy)fluorination roughens the fibre surface, specific surface area (SSA from BET method) can either slightly increase (increase of $0.3-0.4 \mathrm{~m}^{2} / \mathrm{g}$ ) and be linked to a tiny surface roughening [56], or drastically raise (from $0.22-0.47$ to $33-38 \mathrm{~m}^{2} / \mathrm{g}$ ), evidencing a surface damaging [67]. Partial exfoliation may be kept in mind to explain huge increase of the SSA. If important enough (at least $5-10 \mathrm{~m}^{2} / \mathrm{g}$ ), this roughening could enhance the fibre-matrix adhesion in composite, by mechanical interlocking [56].

When both roughening and smoothing occur, roughening has been reported to happen before smoothing [54]; the latter one has been attributed to a fibre desizing by decomposition under fluorine of the sizing [73].

Correlate surface porous structure of fibrous materials and properties is still an important but difficult issue. As a matter of fact, SSA of carbon fibres is effected by plenty of factors like their average length and degree of packing density but there is a lack a data. It this section, only the available data are discussed.

\subsection{Wettability properties}

One of the remarkable properties of the (oxy)fluorination of carbon fibres is to confer them a hydrophobic or hydrophilic behaviour, depending on the chosen experimental conditions and the nature of formed C-F bond. Such modifications of the surface energy can be useful to tailor (oxy)fluorinated carbon fibres as reinforcements in polymers or fluoropolymers.

The wettability of carbon fibres with several liquids seems to be enhanced under mild (oxy)fluorination conditions. This behaviour has been reported in several studies with water [3,58,64-66,113], glycerol [109] or fluoropolymers [72]. This enhanced wettability has been linked with a drastic increasing of the polar component of the surface energy [58,64-66], leading to an increase of the total surface energy, despite a slight decrease of the dispersive component.

The increase of the polar component has been attributed to the formation of C-O hydrophilic bonds and C-F semi-covalent bonds [64-66], which can be evidenced in Figure 4. On the other hand, the decrease of the dispersive component could be explained by the disappearance of the graphitic character induced by fluorination [58]. As previously discussed, some (oxy)fluorination parameters were mild enough to induce hydrophilicity, as reported in the Table 8, rather than hydrophobicity as expected due to the presence of $\mathrm{F}$ atoms. 
Table 8: Selection of experimental conditions leading to hydrophilicity enhancement

\begin{tabular}{cccccc}
\hline $\begin{array}{c}\text { Fluorination } \\
\text { method }\end{array}$ & $\begin{array}{c}\text { Temperature } \\
\left({ }^{\circ} \mathrm{C}\right)\end{array}$ & $\begin{array}{c}\text { Pressure } \\
(\mathrm{kPa})\end{array}$ & Duration & Gas & $\begin{array}{c}\text { Source } \\
\text { (experiment } \\
\text { reported as })\end{array}$ \\
\hline Direct & $25-110$ & $130-2600$ & $1-60 \mathrm{~h}$ & $\mathrm{~F}_{2}$ or $\mathrm{ClF}_{3}$ & $\begin{array}{c}\mathrm{n}^{\circ} 16,17,19 \\
\text { in Table 6 }\end{array}$ \\
\hline Direct & 25 & 1.3 & $3-20 \mathrm{~min}$ & $\mathrm{~F}_{2}$ & {$[113]$} \\
\hline Direct & $\mathrm{RT}$ & 5 & $30 \mathrm{~min}$ & $\begin{array}{c}\mathrm{F}_{2} / \mathrm{O}_{2}\left(0.5 \mathrm{O}_{2}\right. \\
\text { mole fraction })\end{array}$ & {$[65]$} \\
\hline Direct & $\mathrm{RT}$ & 5 & $5-10 \mathrm{~min}$ & $\begin{array}{c}\mathrm{F}_{2} / \mathrm{O}_{2}\left(0.5 \mathrm{O}_{2}\right. \\
\text { mole fraction })\end{array}$ & {$[66]$} \\
\hline Direct & $25-100$ & 200 & $10 \mathrm{~min}$ & $\begin{array}{c}\mathrm{F}_{2} / \mathrm{O}_{2} \\
(50 \% / 50 \%)\end{array}$ & {$[3]$} \\
\hline Direct & $\mathrm{RT}$ & 5 & $30 \mathrm{~min}$ & $\begin{array}{c}\mathrm{F}_{2} / \mathrm{O}_{2}\left(0.5 \mathrm{O} \mathrm{O}_{2}\right. \\
\text { mole fraction })\end{array}$ & {$[64]$} \\
\hline
\end{tabular}

On the other hand, as expected, an increased hydrophobicity of the carbon fibres can be caused by fluorination. This enhanced hydrophobicity notably leads to a decreased wettability, higher contact angles $(\theta)$ and a decrease of the surface energy. Two possibilities can be considered: the treatment can either directly confer a hydrophobic behaviour to the carbon fibre $[54,56,61,67,114]$, or can firstly confer hydrophilic properties such as seen previously, and then render the fibre more hydrophobic when a parameter is modified, e.g. temperature [3], fluorine content [58], treatment duration and pressure [113], or the gas mixture composition $[54,64,65]$.

In the first case, this behaviour can be explained by high $\mathrm{F} / \mathrm{C}$ ratios [67], by the absence of hydrophilic ionic C-F bonds [67] and by the uncovering of the carbon fibres by sizing degradation [61]. The experimental conditions leading to this immediate hydrophobicity increase are reported in Table 9.

Table 9: Selection of experimental conditions leading to a hydrophobicity increase

\begin{tabular}{|c|c|c|c|c|c|}
\hline $\begin{array}{c}\text { Fluorination } \\
\text { method }\end{array}$ & $\begin{array}{c}\text { Temperature } \\
\left({ }^{\circ} \mathrm{C}\right)\end{array}$ & $\begin{array}{l}\text { Pressure } \\
(\mathrm{kPa})\end{array}$ & Duration & Gas & $\begin{array}{c}\text { Source; } \\
\text { (experiment } \\
\text { reported as) }\end{array}$ \\
\hline- & 100 & 101.3 & - & $\mathrm{F}_{2}$ & [114] \\
\hline Direct & 378 & $\begin{array}{l}101.3(20 \\
\mathrm{mL} / \mathrm{min})\end{array}$ & $15-30 \mathrm{~min}$ & $\begin{array}{c}\mathrm{N}_{2} / \mathrm{F}_{2} \\
(90 \% / 10 \%) \\
(\mathrm{HF}<5 \% \text { in } \\
\text { fluorine gas) }\end{array}$ & $\begin{array}{l}\mathrm{n}^{\circ} 1-8 \text { in } \\
\text { Table } 6\end{array}$ \\
\hline Direct & 25 & - & $180 \mathrm{~s}$ & $\begin{array}{c}\mathrm{F}_{2} / \mathrm{O}_{2} / \mathrm{N}_{2} \\
(1 \% / 18 \% / 81 \% \\
- \\
10 \% / 0 \% / 90 \%)\end{array}$ & [61] \\
\hline APF & - & $\begin{array}{c}101.3 \text { (gas } \\
\text { pressure: } 230 \\
\text { kPa at } 35 \\
\text { L/min) }\end{array}$ & $\begin{array}{l}4 \text { min } \\
\text { (continuous } \\
\text { and batch) }\end{array}$ & $\begin{array}{c}\text { Ionised } \\
\mathrm{CHClF}_{2} / \mathrm{N}_{2} \\
(1: 70)\end{array}$ & [56] \\
\hline APF & - & $\begin{array}{c}101.3 \text { (gas } \\
\text { pressure: } 280\end{array}$ & $4 \mathrm{~min}$ & $\begin{array}{c}\text { Ionised } \\
\mathrm{CHClF}_{2} / \mathrm{N}_{2} \\
\end{array}$ & [54] \\
\hline
\end{tabular}




$\begin{array}{cc}-350 \mathrm{kPa} \text { at } & (0.15 \% \text { of } \\ 30 \mathrm{~L} / \mathrm{min}) & \left.\mathrm{CHClF}_{2}\right)\end{array}$

In the second case, the decrease of the wettability, while the chosen treatment initially favours hydrophilicity of the fibre, can be explained by several parameter variations:

- The carbon fibre nature may be involved; despite close fluorination treatments, it has been reported than Sigri fibres adopted a hydrophilic behaviour, while Torayca fibres became more hydrophobic. The treatments compared here are $\mathrm{C} 1$ and $\mathrm{T} 1 \mathrm{in}$ [58]. It highlights the following fact: a treatment that renders some fibres more wettable can confer a hydrophobic behaviour to other fibres.

- The treatment duration acts too; if short fluorination duration ( $3 \mathrm{~min}$ ) has been found to decrease the contact angle with water, longer durations (20 to $120 \mathrm{~min}$ ) have led to a higher contact angle compared to the short fluorination one: $\theta_{3 \text { min }}<\theta_{20 \min }<\theta_{120 \min }$ $<\theta_{\text {non fluorinated }}[113]$.

- An increase in the treatment pressure has been reported as a way to increase the contact angle. Slight increases of the contact angle with water have been reported in [113] when increasing the pressure from 10-30 to 50-100 $\mathrm{mmHg}$, while increasing the pressure of the reactant gas from 5 to $10-80 \mathrm{kPa}$ has led to a huge increase of the contact angle [65], as reported in Table 10. In the same study, the polar component of the surface energy has followed the exact opposite trend while the dispersive component has barely changed, leading the total surface energy to evolve as the polar component.

Table 10: Evolution of the contact angle with water of oxyfluorinated fibres with pressure (values from [65])

\begin{tabular}{ccccccc}
\hline $\begin{array}{c}\text { Reaction } \\
\text { pressure }(\mathrm{kPa})\end{array}$ & Untreated & 5 & 10 & 20 & 40 & 80 \\
\hline $\begin{array}{c}\text { Contact angle } \\
\text { with water }\left(^{\circ}\right)\end{array}$ & 113 & 45 & 55 & 85 & 115 & 115 \\
\hline
\end{tabular}

- The contact angle with water depends on the treatment temperature. As a matter of fact, oxyfluorinations above $100^{\circ} \mathrm{C}$ led to an angle increase, while the hydrophilicity was initially increased by this temperature hike [3]. As reported in Table 11, polar ratios $X_{p}=\gamma_{p} / \gamma$, where $\gamma$ is the surface energy and $p$ stands for "polar", have been found to follow the opposite trend. This evolution could notably be explained by a C$\mathrm{F}$ bond nature modification [3], as previously seen in section 2 .

Table 11: Contact angle with water and polar ratio evolution of oxyfluorinated fibres with temperature (values from [3])

\begin{tabular}{cccccc}
\hline $\begin{array}{c}\text { Reaction } \\
\text { temperature }\left({ }^{\circ} \mathrm{C}\right)\end{array}$ & Untreated & RT & 100 & 300 & 400 \\
\hline $\begin{array}{c}\text { Advancing contact } \\
\text { angle with water }\left(^{\circ}\right)\end{array}$ & 83 & 80 & 78 & 88 & 90 \\
\hline Polar ratio $X_{p}$ & 0.07 & 0.22 & 0.28 & 0.25 & 0.24 \\
\hline
\end{tabular}

- The reactant gas play a role on the wettability, as reported in [54], where APF fibres with $\mathrm{SF}_{6} / \mathrm{N}_{2}\left(0.15 \%\right.$ of $\left.\mathrm{SF}_{6}\right)$ have become more hydrophilic than the untreated fibres 
with a higher surface energy, while fluorinated fibres with $\mathrm{CHClF}_{2} / \mathrm{N}_{2}(0.15 \%$ of $\mathrm{CHClF}_{2}$ ) have become clearly hydrophobic, with a lower surface energy, as reported in Table 12.

Table 12: Contact angle with water and surface energy of 4 min APF carbon fibres depending on the reactant gas (values from [54])

\begin{tabular}{cccc}
\hline Reactant gas & Untreated & $\mathrm{SF}_{6} / \mathrm{N}_{2}$ & $\mathrm{CHClF}_{2} / \mathrm{N}_{2}$ \\
\hline $\begin{array}{c}\text { Contact angle with } \\
\text { water }\left({ }^{\circ}\right)\end{array}$ & 73 & 61 & 103 \\
\hline Surface energy $(\mathrm{mN} / \mathrm{m})$ & 44 & 48 & 31 \\
\hline
\end{tabular}

Moreover, it has been found in [65] that the oxyfluorination of carbon fibres confers them an optimal hydrophilicity when the $\mathrm{F}_{2} / \mathrm{O}_{2}$ reactant gas is containing 0.5 mole fraction of oxygen (sample $\mathrm{n}^{\circ} 3$ in Table 7). Modifying this mole fraction has led to an increase of the contact angle with water, and to a decrease of the surface energy. This observation seems coherent with Figure 4, as the sample $\mathrm{n}^{\circ} 3$ is the one with the highest content of semi-ionic C-F bonds, known to be more hydrophilic than covalent ones.

This part, where several studies about wettability of (oxy)fluorinated carbon fibres were reviewed, highlighted the dependence on the chosen experimental conditions and formed $\mathrm{C}-\mathrm{F}$ bonds; different behaviours exist and the surface energy may be tailored in order to either enhance the hydrophilicity of the fibre while increasing the surface energy, or confer them hydrophobic properties (decrease of the surface energy).

\subsection{Surface acidity}

The few studies interested in the surface acidity of (oxy)fluorinated carbon fibres point out the same result: (oxy)fluorination tends to acidify their surface. This has been highlighted thanks to three main parameters: the isoelectric point (iep), which focuses on the external surface charges [115] and obtained through the $\zeta=\mathrm{f}(\mathrm{pH})$ curve, the $\mathrm{pH}$, and the acid value. The latter value is the mass of potassium hydroxide $(\mathrm{KOH})$ in milligrams that is required to neutralize one gram of a chemical substance.

The acid and $\mathrm{pH}$ values have thus been found to evolve respectively from $15 \mathrm{meq} . \mathrm{g}^{-1}$ to 18.2 22.1 meq. $\mathrm{g}^{-1}$ and from 7.02 to 6.95 , after oxyfluorination at various temperatures, from RT to $300^{\circ} \mathrm{C}$. This slight acidification of the fibres have been attributed to the formation of acid groups, such as carboxyl or carbonyl, created because oxygen acts as an oxidant during the treatment $[3,62,63]$. This hypothesis is strengthened by FT-IR spectroscopy highlighting the presence of $\mathrm{OH}$ and $\mathrm{C}=\mathrm{O}$ groups at the surface of oxyfluorinated fibres in [3].

The iep evolution has been found to decrease from 3.7 to 2.8 under APF treatment, evidencing a surface acidification which has been attributed to an increase of the number of carboxyl groups after APF, despite a decrease of the relative content of surface oxygen atoms [54]. Similar results have been obtained in [67], where the iep decreased from 3.6 to 3.2 (samples $\mathrm{n}^{\circ}$ 5-8 of Table 6). On the other hand, in the same study, the iep has not been lowered for the other tested kind of fibres (samples $n^{\circ} 1-3$ of Table 6), except for the heavier fluorination treatment (sample $\mathrm{n}^{\circ} 4$ of Table 6). In both cases, the scattering of the $\zeta_{\text {plateau }}$ values has been assigned to the variation of the amount of - $\mathrm{COOH}$ groups, and eventually from a high desorption of $\mathrm{F}^{-}$from the fibre bulk for severely fluorinated fibres. 


\section{$5 \quad$ Structural and bulk properties induced by fluorination}

In order to know how the (oxy)fluorination affects the structure of the fibres, several analyses were carried out, such as X-Ray Diffraction (XRD), Raman spectroscopy, and Scanning Electron Microscopy (SEM) or simply by measuring the fibre diameter. These analyses allow the extension of (oxy)fluorination of the fibre to be evidenced, i.e. either a surface grafting of heteroatoms or diffusion into the bulk.

\section{$5.1 \quad$ Structural properties}

\subsubsection{Fluorinated layer depth}

The depth of fluorinated layer can be estimated by considering the fibre as a two-phase material, one phase being the external perfluorinated layer, the other one being the internal slightly-fluorinated layer. It has been established that the fluorine repartition in the carbon material can be determined by calculating the ratio $[F / C]_{X P S} /[F / C]_{E A}$, where $[F / C]_{X P S}$ and $[F / C]_{E A}$ are the surface and whole fibre composition, respectively [116].

Three hypotheses are necessary to estimate the fluorinated layer depth:

- The external layer is homogeneously fluorinated, meaning that the XPS ratios characterise the whole layer. The fluorinated layer depth is $d_{F L}$.

- The fibre bulk is not fluorinated, meaning that all the fluorine detected in EA comes from the external layer.

- The fluorination is homogeneous along the fibre longitudinal axis, which allows to consider only the fibre cross section.

$\mathrm{D}$ and $\mathrm{S}$ respectively stand for diameter and section, and the subscripts WF, NFB, and FL respectively stand for "whole fibre", "non-fluorinated bulk", and "fluorinated layer". The fluorine repartition in the fibre section can then be written as follows:

$$
[F / C]_{E A} S_{W F}=[F / C]_{X P S} S_{F L}
$$

This equation can be developed as:

$$
S_{F L}=\frac{\pi\left(D_{W F}^{2}-D_{N F B}^{2}\right)}{4}=\frac{\pi D_{W F}^{2}}{4} \frac{[F / C]_{E A}}{[F / C]_{X P S}}
$$

And can be rewritten as:

$$
D_{N F B}^{2}=D_{W F}^{2}\left(1-\frac{[F / C]_{E A}}{[F / C]_{X P S}}\right)
$$

Meaning that:

$$
d_{F L}=D_{W F}-D_{N F B}=D_{W F}\left(1-\sqrt{1-\frac{[F / C]_{E A}}{[F / C]_{X P S}}}\right)
$$

Using the latter equation, the fluorinated layer depths of carbon fibres from various studies are given in Figure 6, using the data from these studies, whose experimental conditions are given in Table 6 (samples $n^{\circ} 1-8, n^{\circ} 16-21$, and $n^{\circ} 25-28$ ). The 5 last samples of Figure 6 come from [62], where the fibres have been (oxy)fluorinated with pure $\mathrm{F}_{2}$ (referred as $\mathrm{CF}$ ) or a 50/50\% vol. $\mathrm{F}_{2}: \mathrm{O}_{2}$ mixture (referred as $\mathrm{CFO}$ ) for 10 minutes at various temperatures $\left(\mathrm{RT}, 100^{\circ} \mathrm{C}\right.$, $300^{\circ} \mathrm{C}, 400^{\circ} \mathrm{C}$ ), with a $\mathrm{F}_{2}$ pressure set at $0.2 \mathrm{MPa}$. Several factors seem to influence $d_{F L}$ : 
- The latter one appears to increase with the fluorination time, as evidenced by T300T700 samples: the only difference between T300B, T300C, T300D and T300E is their increasing fluorination time, and so does $d_{F L}$. The same conclusion can be made for T700 fibres.

- The fluorinating gas mixture is also determining, as highlighted by oxyfluorinated samples, which exhibit deeper fluorinated layers than fluorinated samples: CFO-RT, CFO-20 and CFO-125 have respectively $d_{F L}$ of $0.39,0.37$, and $0.28 \mu \mathrm{m}$, against only $0.14,0.12$ and $0.09 \mu \mathrm{m}$ for CF-RT, CF-20 and CF-125. This depth increase could notably be explained by the fluorination intercalation enhancement allowed by the presence of a Lewis acid $\left(\mathrm{O}_{2}\right.$ here $)$, as already explained in section 2 . It has however been shown through XRD analyses in $[3,65,66]$ that oxyfluorination globally takes place at the fibre surface, meaning that the calculated depths in this review could be overestimated.

- Other fluorinating gas mixtures, such as $10 / 90 \%$ vol. $\mathrm{HF}: \mathrm{F}_{2}(\mathrm{C} 3)$ and $\mathrm{ClF}_{3}(\mathrm{C} 4)$, resulted in deeper fluorinated layers when compared to pure fluorine. It should however be noted that $\mathrm{C} 4$ fibres have been fluorinated during $60 \mathrm{~h}$, which is much longer than $\mathrm{C} 1$ or $\mathrm{C} 2$ fibres. Catalytic effect of gaseous $\mathrm{HF}$ and $\mathrm{MF}_{\mathrm{n}}$ species are well known for graphitized samples [99,103].

- Temperature seems to have an influence on $d_{F L}$, as shown by the depths of CFO-RT, CFO-100, CFO-300 and CFO-400 fibres, their only difference being their oxyfluorination temperature: there is a gap between fibres fluorinated under and above $300^{\circ} \mathrm{C}$. High temperatures could then possibly increase the fluorinated layer depth. This hypothesis is strengthened by the depth similarity of CF-20 and CF-125, 0.12 against $0.09 \mu \mathrm{m}$ : temperature did not seem to be a depth increaser for these fluorinations under $300^{\circ} \mathrm{C}$.

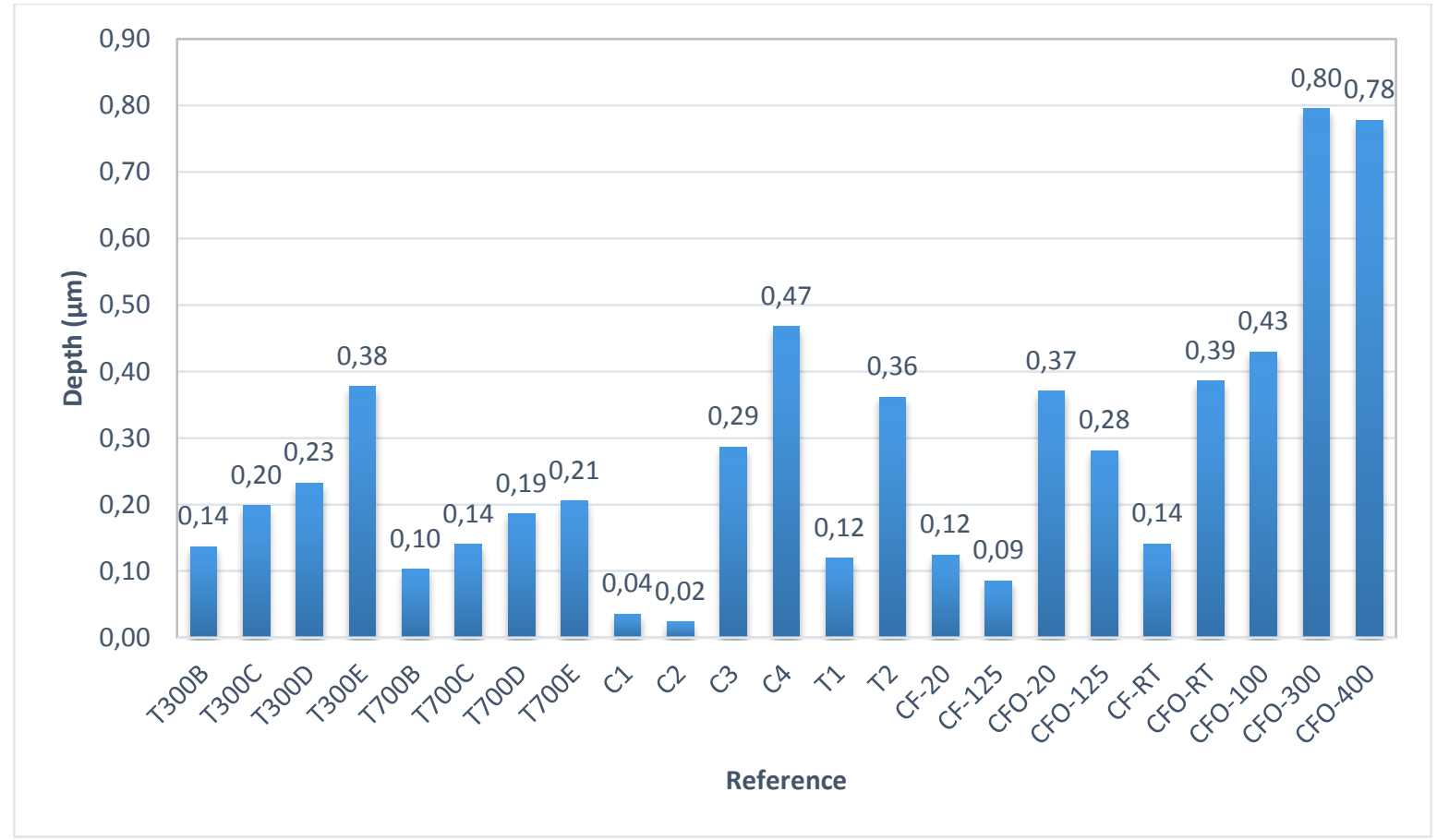

Figure 6: Fluorinated layer depth depending on the sample

It should be noted that the emitted hypotheses probably lead to an overestimation of the fluorine content into the fluorinated layer, as it has been assumed to be the $[F / C]_{X P S}$ one in the whole layer, with all the fluorine of $[F / C]_{E A}$ coming from this layer. In reality, the layer 
containing fluorine is probably deeper, with a maximal fluorine concentration $[F / C]_{X P S}$ only at its extreme surface, and a decreasing concentration of fluorine while progressing in the fibre bulk, to finally end and let some graphitic carbon non-fluorinated. The two discussed structures are presented in Figure 7.

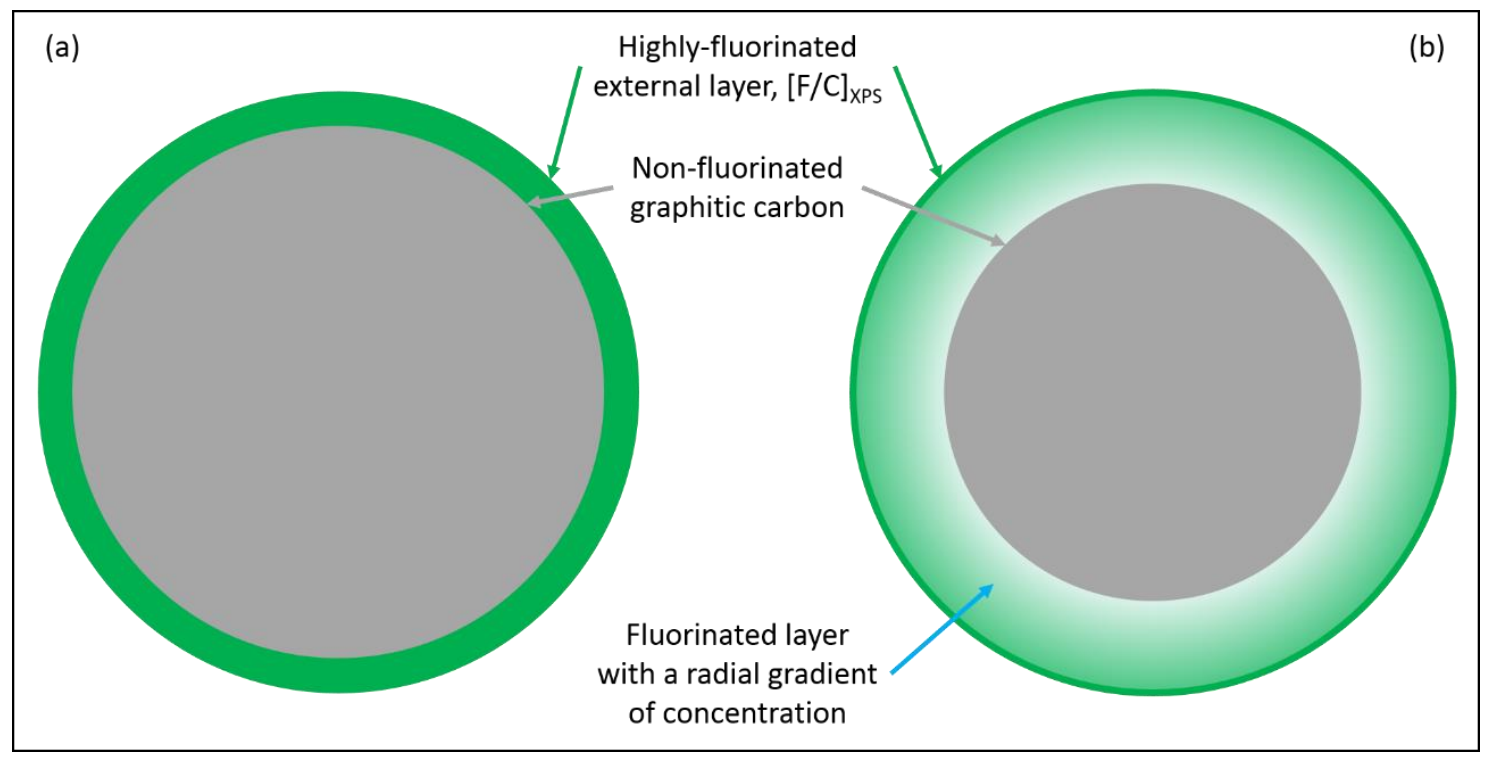

Figure 7: Fluorinated carbon fibre structure, (a) according to the previous hypotheses, (b) most probable structure

\subsubsection{Raman observations}

Carbonaceous materials exhibit two main peaks during Raman analysis. The first one (Gband), around $1580 \mathrm{~cm}^{-1}$, is assigned to the graphitic structure of carbon, while the second one (D-band), around $1350 \mathrm{~cm}^{-1}$, is attributed to disordered finite-size microcrystalline carbon [117]. The ratio of their intensities, $\mathrm{I}_{\mathrm{D}} / \mathrm{I}_{\mathrm{G}}$, highlights the amount of defective and crystalline mode in the carbon fibre sample.

Some studies have observed a decrease of $\mathrm{I}_{\mathrm{D}} / \mathrm{I}_{\mathrm{G}}$ ratio under APF, and have linked it to the carbon sputtering, leading to the removal of surface amorphous carbon by the plasma jet, and to the emergence of graphitic carbon at the fibre surface $[54,56]$. On the other hand, fluorinations of carbon fibres under high temperatures have led to $\mathrm{I}_{\mathrm{D}} / \mathrm{I}_{\mathrm{G}}$ increases from 1.061.08 to $1.17-1.23$, that highlights an increase of the fibre disorder during fluorination [67].

To guarantee a specific analysis of the fluorinated phase, the detection depth of Raman laser should not be greater than the depth of the fluorinated layer, otherwise non-fluorinated graphitic carbon would also be analysed. The penetration depth $d_{p}$ of Raman laser is known as $d_{p}=2 / 2.3 \alpha(\lambda)$, with $\alpha$ the photoabsorption coefficient of the penetrated material [118], and $\lambda$ the Raman laser wavelength. The evolution of $\alpha$ depending on $\lambda$ for graphite is given in [119] and allows to gather in Table 13 depth penetrations of Raman laser depending on its wavelength for the articles studied in this section (5.1.2). 
Table 13: Depth penetrations of Raman lasers in graphitic materials depending on their wavelengths

\begin{tabular}{cccc}
\hline Reference & $\begin{array}{c}\text { Raman wavelength } \\
\lambda(\mathrm{nm})\end{array}$ & $\begin{array}{c}\text { Photoabsorption } \\
\text { coefficient } \alpha\left(\mu \mathrm{m}^{-1}\right)^{3}\end{array}$ & $\begin{array}{c}\text { Depth } \\
\text { penetration } \boldsymbol{d}_{\boldsymbol{p}}(\mu \mathrm{m})\end{array}$ \\
\hline$[67]$ & 532 & $5.5-7.5$ & $0.18-0.23$ \\
\hline$[54,56]$ & $633-634$ & $5.0-6.5$ & $0.15-0.21$ \\
\hline
\end{tabular}

It can be seen in Table 13 that if the Raman laser penetration depth is $0.18-0.23 \mu \mathrm{m}$ for the fluorinated fibres in [67], the fluorinated layer depths are 0.10-0.38 $\mu \mathrm{m}$ (T300 and T700 fibres), meaning that for some fluorinated fibres, the Raman analysis also includes graphitic non-fluorinated carbon, according to these calculations. However, as mentioned in 5.1.1, the fluorinated layer real depth may be superior to the calculated values.

\subsubsection{X-Ray Diffraction evolutions}

XRD diagrams in various works $[3,58,65,66,73]$ about (oxy)fluorinations under mild conditions, reported in Table 1, were barely changed, evidencing that (oxy)fluorination was only taking place at the fibre surface because of the rigidity of the graphitic lattice, which is able to resist to intercalation or bulk fluorination under these conditions.

However, it has been highlighted by XRD that depending on the treatment severity, fluorination could also take place in the bulk of the fibre. Indeed, increasing the treatment duration and pressure (samples $n^{\circ} 22-24$ in Table 6 ) has led to a broadening of the 002 peak of the graphitic phase, that indicates the diffusion of fluorine in the bulk of the fibres and a disorder increase, while the slightly fluorinated fibres had the same XRD pattern than the nonfluorinated ones, meaning that fluorine was rather involved in covalent C-F bonding with unsaturated carbon atom defects present at the surface.

The influence of treatment duration on diffractograms has also been reported in [67], where increasing the fluorination time has led to two interesting phenomena: firstly, a shift of the 002 peak to higher $2 \theta$ angles, indicating a bulk fluorination of the fibres, has been reported (samples $n^{\circ 7-8}$ of Table 6). Secondly, the emergence of two new peaks in the XRD patterns has been observed (samples $n^{\circ} 3-4$ and $n^{\circ} 7-8$ of Table 6 ). The first one, around $10-15^{\circ}$ associated with an interlayer of 6.5-7.4 nm, has been attributed to the 001 plane and to the formation of a fluorocarbon lattice, while the second one, at $44^{\circ}$, corresponds to the $100 / 101$ lines of the graphitic structure. In this study, contrarily to the previous paragraph, a narrowing of the 002 peak, indicating an increase of the crystallite size $L_{C}$, has been observed when the fluorination duration increases [67]. This evidences that the fluorination focused on the less ordered graphitic phases keeping the zones with higher crystallinity unchanged with their high $L_{C}$, as already reported in [95].

Another study, using XRD patterns to follow fluorine intercalation into carbon fibres, has highlighted that the use of HF in the reactant gaseous mixture leads to a preferential fluorine intercalation than a fluorination using pure fluorine, as reported in section 3 . Rather than involved in a covalent $\mathrm{C}-\mathrm{F}$ bond, fluorine has been preferentially intercalated in the carbonaceous lattice, increasing the disorder and broadening the peaks of the XRD pattern [120]. In accordance with this, changing the reaction atmosphere from pure fluorine to $\mathrm{HF} / \mathrm{F}_{2}$

\footnotetext{
${ }^{3}$ Graphically obtained in [119]
} 
(1:10) mixture has led to the appearance of a XRD peak around $21^{\circ}$ in another study, which indicates the formation of stage $3 \mathrm{C}_{x} \mathrm{~F}$ [58].

XRD appears as a way to study the way the fluorine interacts with the bulk and the surface of the carbon fibres. Under standard conditions (direct fluorination under pure fluorine at room temperature), fluorine rather bonds to the fibre surface than diffuses into the bulk. Whatever the route, the fluorine interacts with the carbon fibre and allows a wettability evolution, as described in section 4.3 .

\subsection{Electrical properties}

The electrical properties, resistance $\mathrm{R}$, resistivity $\rho$, or conductivity $\sigma$, the latter one being the most studied in literature, evolve with both the fluorination degree and the C-F bonding [66]. As a matter of fact, fluorine intercalation leads to enhanced conductivity, while formation of graphite fluoride tends to decrease conductivity. In both cases, these phenomena are explained by changes in the $\pi$-electron system of the graphitic part of carbon fibres [66], which implies major modifications of the fibre bulk properties due to diffusion of fluorine [54].

This assumption has also been reported in [58], where mild fluorinations have led to conductivity increases, while the more severe ones have decreased it: the conductivity of pristine fibres was $530 \mathrm{~S} . \mathrm{cm}^{-1}$, while the one of slightly fluorinated fibres was $600-630 \mathrm{~S}^{-\mathrm{cm}^{-1}}$ (samples $\mathrm{n}^{\circ} 16-17$ in Table 6) and the one of strongly fluorinated fibres dropped to $110{\mathrm{~S} . \mathrm{cm}^{-1}}^{-1}$ Resistivity and resistance have changed as followed: a weak decrease for slight fluorinations (from $1.9 \Omega . \mathrm{cm}$ to $1.6-1.7 \Omega . \mathrm{cm}$ for resistivity and from $7.3 \mathrm{k} \Omega$ to $6.7-7.3 \mathrm{k} \Omega$ for resistance), followed by a significant increase for severe fluorinations (respectively $9.15 \Omega . \mathrm{cm}$ and 38 $\mathrm{k} \Omega)$.

Similar results have been observed in [67], where the formation of covalent C-F bonds have decreased the conductivity from $640 \mathrm{~S} . \mathrm{cm}^{-1}$ for pristine fibres to $580-590{\mathrm{~S} . \mathrm{cm}^{-1}}^{-1}$ for fluorinated fibres (samples $n^{\circ} 3-4$ in Table 6). On the other hand, the intercalation of

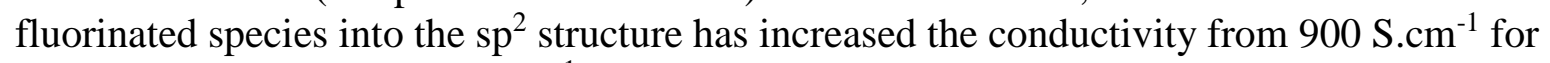
pristine fibres to 990-1020 S.cm ${ }^{-1}$ for fluorinated fibres (samples $\mathrm{n}^{\circ} 5$ and $\mathrm{n}^{\circ} 7$ in Table 6).

These important conductivity decreases have been explained by the change of the carbon hybridization from $\mathrm{sp}^{2}$ to $\mathrm{sp}^{3}$, which is due to the fluorination of the fibre bulk and to the formation of graphite fluoride already raised in this section [58]. This assumption is strengthened by the fact that high-temperature fluorinated fibres, where fluorine is covalently bonded to $\mathrm{sp}^{3}$ carbon through $(\mathrm{CF})_{\mathrm{n}}$ and $\left(\mathrm{C}_{2} \mathrm{~F}\right)_{\mathrm{n}}$ phases, are known to be insulators, while lowtemperature $\left(<100^{\circ} \mathrm{C}\right)$ fluorinated carbon fibres, where fluorine is intercalated in the graphitic $\mathrm{sp}^{2}$ lattice as a GIC, exhibit excellent conductivities [96]. More precisely, fibres containing stage-2 GICs, which are produced under $F_{2}$ pressures lower than 10 bars, have higher conductivities, while fibres hosting stage-1 GICs, obtained under severe conditions (fluorine pressure of 10 bars) have a much higher resistivity than pristine fibres, around one order of magnitude [120].

To summarize, mild fluorination conditions slightly improve the conductivity while severe conditions lower it drastically.

\subsection{Mechanical properties}

Regarding the structural changes which may be important in particular fluorination conditions, the mechanical properties of carbon fibres must be investigated as they can change drastically. Several studies have investigated the evolution of the mechanical properties 
(tensile strength and Young's modulus) of carbon fibres with (oxy)fluorination. Table 14 computes these studies as well as their tensile test conditions.

Table 14: Tensile test conditions of (oxy)fluorinated carbon fibres in literature

\begin{tabular}{cccc}
\hline Reference & Gauge length $(\mathrm{mm})$ & Testing rate $(\mathrm{mm} / \mathrm{min})$ & $\begin{array}{c}\text { Number of } \\
\text { measurements }\end{array}$ \\
\hline $\begin{array}{c}\text { [56] (25-29 in } \\
\text { Table 5) }\end{array}$ & $20-50$ & 0.01 & 25 \\
\hline [61] & 10 & 10 & 100 \\
\hline$[67](5-8$ in Table 6) & 25 & 0.01 & 20 \\
\hline$[59](25-28$ in Table 6) & 20 & 1 & 20 \\
\hline$[60](22-24$ in Table 6) & 20 & 1 & 20 \\
\hline
\end{tabular}

The data are disparate. On the one hand, sharp increases of ultimate tensile strength (UTS) and Young's modulus have been observed. The UTS and Young's modulus of fibres oxyfluorinated at $125^{\circ} \mathrm{C}$ have indeed been reported to respectively gain $36 \%$ and $32 \%$ when compared to the ones of pristine fibres [59]. Similar results have been observed on $\mathrm{F}_{2}-\mathrm{HF}$ fluorinated fibres, with increases of $40 \%$ and $30 \%$ for UTS and Young's modulus respectively [60], and on RT oxyfluorinated fibres, with 12-20\% increases of the UTS. These increases were explained by both a diameter decrease of the fluorinated fibres [61], which allows a better alignment of the fibre structure [59,60], and by the removal of surface defects by fluorination $[59,60]$.

On the other hand, important decreases of the mechanical properties have been reported. The UTS of carbon fibres fluorinated with $\mathrm{BrF}_{5}$ for 30 days have been divided by two (from 2.2 $\mathrm{GPa}$ to $1.02 \mathrm{GPa}$ ) [109], while the one of high temperature fluorinated fibres have decreased by $33 \%$, and their Young's modulus by $20 \%$ [67]. Several factors can explain these decreases: severe fluorination results in damages in both the surface and formation of pit holes [67]. Moreover, the diffusion of fluorine into the fibre bulk [67] and the buckling of $\mathrm{sp}^{3} \mathrm{C}-\mathrm{F}$ layers compared to the $\mathrm{sp}^{2}$ graphitic layers, affect the fibre preferred orientation because of an increase of the interplanar spacing and of a decrease of coherence lengths $L_{a}$ and $L_{C}$ [121]. The resulting decreases of the mechanical properties do not obligatory disqualify the fluorinated fibre for reinforcement of composite, thanks to the other obtained properties, for instance adhesive [109] or hydrophobic ones.

Another interesting parameter which is generally decreasing with the fibre fluorination is Weibull modulus [56,61], which quantifies the homogeneity of defect dispersion. Its decrease implies that fluorination increases the heterogeneity of defect dispersion, which could lead to early breakings.

It is to note that the mild fluorination treatments, such as APF or fluorination located only on sizing, allow the mechanical properties of the fibres to be maintained [56,73]. In this case, one could think that these fluorinations did not lead to the formation of critical surface flaws nor to a diameter evolution.

In this part, the mechanical properties of (oxy)fluorinated carbon fibres have been reviewed. In accordance with the induced structural changes induced, (oxy)fluorination allows the mechanical properties to be enhanced if the structure is slightly affected. On the contrary, strong (oxy)fluorination treatments result in drastic rearrangement, the mechanical properties are then degraded. 


\subsection{Potential applications for (oxy)fluorinated materials}

(Oxy)fluorinated fibres are almost exclusively used for composite reinforcement. However, another potential application for fluorinated carbonaceous materials is presented here, even if the latter ones are not fibres, in order to give perspectives for the use of these materials.

\subsubsection{Composite reinforcement}

When performed in adequate conditions, fluorination may lead to an enhancement of the wettability through the tailoring of the surface energies, and the maintaining, or even an improvement, of the mechanical properties of carbon fibres as previously highlighted in this review. One could think that all these changes open the way for interaction between fluorinated carbon fibres and polymers and fluoropolymers in composites.

First, it has been reported that fluorination enhances the adhesion with epoxy resins [113], which are the most used matrices with carbon fibres [122]. The adhesion thus increases from $75 \mathrm{~kg} / \mathrm{mm}^{2}$ to $105 \mathrm{~kg} / \mathrm{mm}^{2}$ under the efficient fluorination conditions: a low fluorine pressure is required $(<50 \mathrm{mmHg}$ ), as higher pressures tend to decrease the adhesion down to the initial value between non-fluorinated fibres and epoxy resin. This enhanced adhesion for fluorinated fibres has been related to a higher presence of oxygen-containing groups, which improves the bonding with epoxy.

This enhanced compatibility with a polymer matrix is promising and has also been reported with fluoropolymers. As a matter of fact, the contact angle between carbon fibres and four different liquid fluoropolymers has been reported to decrease from $18.5-19.5^{\circ}$ to $14.2-16^{\circ}$ with an average decrease of $4^{\circ}$, highlighting the fact that fluorinated fibres are more compatible with fluoropolymers than pristine fibres [72]. This compatibility optimisation has been reached with low fluorine content, i.e. surface $\mathrm{F} / \mathrm{C}$ ratio of $0.1-0.2$ ), while high $\mathrm{F} / \mathrm{C}$ ratios of 1.5-1.9 resulted in higher contact angles than with untreated fibres.

This adhesion strengthening leads to an increase of the interfacial shear strength (IFSS), a micromechanical value which characterises the quality and the resistance of the fibre/matrix interface, for example by studying the interfacial resistance of a $\{$ single fibre + matrix $\}$ system $[123,124]$. Fluorination has been reported to increase IFSS between four fluoropolymers and carbon fibres from 8.2-18.4 MPa to 18.7-28.7 MPa, with an average increase of $11.5 \mathrm{MPa}$ [72]. As for the case of contact angle measurements with fluoropolymers, IFSS is enhanced by mild fluorinations, and decreases when fluorination is too extended. The authors have highlighted that an optimal compatibility is reached for fluoropolymers when the "matrix to fibre" fluorination ratio is 9:1, meaning that the matrix must have a F/C ratio 9 times higher than the fibre one [72].

Moreover, fluorination has also been reported to modify macromechanical values, such as the interlaminar shear strength (ILSS), the critical stress intensity factor $\mathrm{K}_{\mathrm{IC}}$, the work of fracture $\mathrm{W}_{\mathrm{f}}$ or the specific fracture energy $\mathrm{G}_{\mathrm{IC}}$. Mild fluorination, i.e. $10 \mathrm{~min}$ at room temperature under pure fluorine, has led to a slight decrease of these values compared to the ones of asreceived carbon fibres, while 10 min of oxyfluorination at various temperatures with $50 \% / 50 \% \mathrm{~F}_{2} / \mathrm{O}_{2}$ gaseous mixture have increased these values, with an optimal treatment temperature of $100^{\circ} \mathrm{C}$ [62]. These macromechanical enhancements have notably been attributed to an increase of the fibre/matrix interfacial adhesion, of the fibre surface acidity and of the wettability; the change of the latter one has been related to an increase of surface polarity. The excellent correlation between the ILSS, $\mathrm{K}_{\mathrm{IC}}$ and the $\left(\mathrm{F}_{1 \mathrm{~S}}+\mathrm{O}_{1 \mathrm{~S}}\right) / \mathrm{C}_{1 \mathrm{~S}}$ ratio has confirmed the effect of the presence of heteroatoms $\mathrm{F}$ and $\mathrm{O}$ [62]. 
Impact properties, such as impact strength, impact energy and ductility index (ratio of the post-peak energy to the energy to peak [125]), have also been reported to be enhanced by the oxyfluorination procedures described just above, especially at a $100^{\circ} \mathrm{C}$ treatment temperature. This improvement of impact properties for oxyfluorinated fibres can be explained by the increase of hydrogen bonding, which hinders impact failure mechanisms and interrupts the development of crack paths into the composite [63].

To conclude this section about the way (oxy)fluorinated carbon fibres bond with (fluoro)polymers, it can be noted that when the fluorination rate is low and involves the formation of oxygen-containing species, the micromechanical interaction between fibres and matrix is enhanced, as seen through both the IFSS increase and the wettability decrease. The conclusion is similar about the wettability and IFSS of weakly fluorinated carbon fibres with fluoropolymers. Concerning the macromechanical properties (ILSS, critical stress intensity factor $\mathrm{K}_{\mathrm{IC}}$, specific fracture energy $\mathrm{G}_{\mathrm{IC}}$, work of fracture $\mathrm{W}_{\mathrm{f}}$, impact properties), the values appear to be enhanced with oxyfluorination, which can notably be explained by an increase of the fibre/matrix interfacial adhesion, of the acidity of the fibre surface, of the fibre wettability, and of hydrogen bonding, which is allowed by the surface chemistry of oxyfluorinated fibres.

\subsubsection{Gas sensing}

In industrial environments, new sensors need to be developed in order to detect toxic gases, e.g. ammonia $\left(\mathrm{NH}_{3}\right)$, at rates as low as possible. The example of $\mathrm{NH}_{3}$ was chosen as ammonia is amongst the most dangerous gases, both for human health and environment [126]. The electrical properties of carbonaceous materials, especially the nanostructured ones [126], change under gas absorption, making them ideal materials for gas sensing applications. Sensors based on CNTs have already allowed the detection of various gases, e. g. $\mathrm{NH}_{3}[127-$ 130] or $\mathrm{CH}_{4}[131,132]$.

In order to increase the reactivity, selectivity and sensitivity of carbonaceous materials to gases [133], they can undergo treatments. Among processes for gas sensing improvement such as acid treatments [134,135], plasma ones [136,137], functionalisation with polymers [138], decoration with nanoparticles [139,140], etc. [141], fluorination exhibits numerous advantages [142-144]. In particular, it increases the SSA of carbon nanomaterials [145]. First, fluorinated graphite oxide (GO), using a HF solution, has thus been reported to have a gas sensing response 20 times higher than pristine GO with a better reversibility [146]. Secondly, fluorinated graphene (FG) exhibits higher adsorption energies [147], higher sensitivity and better adsorption [148] of $\mathrm{NH}_{3}$ than the untreated one. FGs have also been reported to detect a wide variety of molecules other than $\mathrm{NH}_{3}$ [32], such as formaldehyde [149], dopamine [150], heavy metal ions [151] or humidity [152].

This behaviour of fluorinated carbon materials can be explained both by the strength of the hydrogen bonding between fluorine and hydrogen atoms, taking benefits of the electronegativity of F [147], and by the presence of defects in FGs [25]. Fluorine atoms are also known to play a key role in gas adsorption thanks to their p electrons [145], and their ability to change the charge distributions on the functional groups [146], and especially when the fluorination treatment maintains the $\mathrm{sp}^{2}$ state of carbon atoms surrounding the $\mathrm{CF}$ group $[143,153]$. Moreover, it has been highlighted that $\mathrm{NH}_{3}$ and $\mathrm{NO}_{2}$ are adsorbed by fluorine atoms, hydroxyl groups, and carbon atoms close to the functional groups [32].

\section{Conclusions}


In this review, the $\mathrm{C}-\mathrm{F}$ bonding in carbon fibres was first investigated, evidencing its versatility, which depends on the fluorination conditions and the presence of dioxygen in the reactive gaseous mixture. The surface fluorine content has also been carefully reviewed through the computation of numerous XPS studies. Using these data, an explanation for the changes of both surface and structural properties with fluorination is proposed. The diversity of both the treatment conditions (composition of the reactive mixture, temperature, pressure, duration) and the type of starting fibres complicates the generalization. Several antagonist phenomena, such as wettability or electrical evolutions, have been then reported. They act both on the mechanical properties of carbon fibres and on the way the treated fibres bond with polymers in composites. This review also highlights the extraordinary diversity of properties that can be obtained on carbon fibres thanks to (oxy)fluorination and gives the key parameters to select the (oxy)fluorination conditions in order to enhance the desired properties for a particular application, e.g. fillers in composites and sensitive materials in ammonia sensing.

\section{Declaration of competing interest}

The authors declare that they have no known competing financial interests or personal relationships that could have appeared to influence the work reported in this paper.

\section{Acknowledgments}

The authors wish to thank SIGMA Clermont, which has funded this work. SIGMA Clermont did not have any involvement in study design, in the collection, analysis and interpretation of data, in the writing of the report, or in the decision to submit the article for publication.

\section{References}

[1] S. Chand, Review Carbon fibers for composites, J. Mater. Sci. 35 (2000) 1303-1313. https://doi.org/10.1023/A:1004780301489.

[2] P.K. Mallick, Fiber-Reinforced Composites: Materials, Manufacturing, and Design, 3rd ed., CRC Press, 2007. https://doi.org/10.1201/9781420005981.

[3] M.-K. Seo, S.-J. Park, Surface characteristics of carbon fibers modified by direct oxyfluorination, J. Colloid. Interf. Sci. 330 (2009) 237-242. https://doi.org/10.1016/j.jcis.2008.10.005.

[4] L. Servinis, L.C. Henderson, T.R. Gengenbach, A.A. Kafi, M.G. Huson, B.L. Fox, Surface functionalization of unsized carbon fiber using nitrenes derived from organic azides, Carbon. 54 (2013) 378-388. https://doi.org/10.1016/j.carbon.2012.11.051.

[5] S. Tiwari, J. Bijwe, S. Panier, Optimization of surface treatment to enhance fibermatrix interface and performance of composites, Wear. 274-275 (2012) 326-334. https://doi.org/10.1016/j.wear.2011.09.014.

[6] C. Sellitti, J.L. Koenig, H. Ishida, Surface characterization of graphitized carbon fibers by attenuated total reflection fourier transform infrared spectroscopy, Carbon. 28 (1990) 221-228. https://doi.org/10.1016/0008-6223(90)90116-G.

[7] F. Severini, L. Formaro, M. Pegoraro, L. Posca, Chemical modification of carbon fiber surfaces, Carbon. 40 (2002) 735-741. https://doi.org/10.1016/S0008-6223(01)00180-4.

[8] N. Raphael, K. Namratha, B.N. Chandrashekar, K.K. Sadasivuni, D. Ponnamma, A.S. Smitha, S. Krishnaveni, C. Cheng, K. Byrappa, Surface modification and grafting of carbon fibers: A route to better interface, Prog. Cryst. Growth Charact. Mater. 64 (2018) 75-101. https://doi.org/10.1016/j.pcrysgrow.2018.07.001. 
[9] S. Tiwari, M. Sharma, S. Panier, B. Mutel, P. Mitschang, J. Bijwe, Influence of cold remote nitrogen oxygen plasma treatment on carbon fabric and its composites with specialty polymers, J. Mater. Sci. 46 (2011) 964-974. https://doi.org/10.1007/s10853010-4847-z.

[10] P. Kainourgios, I.A. Kartsonakis, D.A. Dragatogiannis, E.P. Koumoulos, P. Goulis, C.A. Charitidis, Electrochemical surface functionalization of carbon fibers for chemical affinity improvement with epoxy resins, Appl. Surf. Sci. 416 (2017) 593-604. https://doi.org/10.1016/j.apsusc.2017.04.214.

[11] J.D. Randall, D.J. Eyckens, L. Servinis, F. Stojcevski, L.A. O’Dell, T.R. Gengenbach, B. Demir, T.R. Walsh, L.C. Henderson, Designing carbon fiber composite interfaces using a 'graft-to' approach: Surface grafting density versus interphase penetration, Carbon. 146 (2019) 88-96. https://doi.org/10.1016/j.carbon.2019.01.064.

[12] G.J. Ehlert, Y. Lin, H.A. Sodano, Carboxyl functionalization of carbon fibers through a grafting reaction that preserves fiber tensile strength, Carbon. 49 (2011) 4246-4255. https://doi.org/10.1016/j.carbon.2011.05.057.

[13] P. Chunzheng, Improving the interfacial property of carbon fiber/PI resin composite by grafting modification of carbon fiber surface, Surf. Interface Anal. 50 (2018) 628-633. https://doi.org/10.1002/sia.6439.

[14] O. Zabihi, M. Ahmadi, S. Shafei, S.M. Seraji, A. Oroumei, M. Naebe, One-step aminofunctionalization of milled carbon fibre for enhancement of thermo-physical properties of epoxy composites, Compos. Part A Appl. Sci. Manuf. 88 (2016) 243-252. https://doi.org/10.1016/j.compositesa.2016.06.005.

[15] Q. Peng, Y. Li, X. He, H. Lv, P. Hu, Y. Shang, C. Wang, R. Wang, T. Sritharan, S. Du, Interfacial enhancement of carbon fiber composites by poly(amido amine) functionalization, Compos. Sci. Technol. 74 (2013) 37-42. https://doi.org/10.1016/j.compscitech.2012.10.005.

[16] K.M. Beggs, M.D. Perus, L. Servinis, L.A. O’Dell, B.L. Fox, T.R. Gengenbach, L.C. Henderson, Rapid surface functionalization of carbon fibres using microwave irradiation in an ionic liquid, RSC Adv. 6 (2016) 32480-32483. https://doi.org/10.1039/C6RA04260K.

[17] E. Moaseri, M. Maghrebi, M. Baniadam, Improvements in mechanical properties of carbon fiber-reinforced epoxy composites: A microwave-assisted approach in functionalization of carbon fiber via diamines, Mater. Des. 55 (2014) 644-652. https://doi.org/10.1016/j.matdes.2013.10.040.

[18] K. Shiba, M. Tagaya, S. Samitsu, S. Motozuka, Effective Surface Functionalization of Carbon Fibers for Fiber/Polymer Composites with Tailor-Made Interfaces, ChemPlusChem. 79 (2014) 197-210. https://doi.org/10.1002/cplu.201300356.

[19] Y. Lin, G. Ehlert, H.A. Sodano, Increased Interface Strength in Carbon Fiber Composites through a ZnO Nanowire Interphase, Adv. Funct. Mater. 19 (2009) 26542660. https://doi.org/10.1002/adfm.200900011.

[20] Y. Liu, Y. Fang, J. Qian, Z. Liu, B. Yang, X. Wang, Bio-inspired polydopamine functionalization of carbon fiber for improving the interfacial adhesion of polypropylene composites, RSC Adv. 5 (2015) 107652-107661. https://doi.org/10.1039/C5RA20045H.

[21] F. De Luca, A.J. Clancy, N. R. Carrero, D.B. Anthony, H.G. De Luca, M.S.P. Shaffer, A. Bismarck, Increasing carbon fiber composite strength with a nanostructured "brickand-mortar" interphase, Mater. Horiz. 5 (2018) 668-674. https://doi.org/10.1039/C7MH00917H.

[22] O. Teraube, J.-C. Agopian, E. Petit, F. Metz, N. Batisse, K. Charlet, M. Dubois, Surface modification of sized vegetal fibers through direct fluorination for eco- 
composites, Journal of Fluorine Chemistry. 238 (2020) 109618.

https://doi.org/10.1016/j.jfluchem.2020.109618.

[23] A.P. Kharitonov, L.N. Kharitonova, Surface modification of polymers by direct fluorination: A convenient approach to improve commercial properties of polymeric articles, Pure Appl. Chem. 81 (2009) 451-471. https://doi.org/10.1351/PAC-CON-0806-02.

[24] A.P. Kharitonov, Practical applications of the direct fluorination of polymers, J. Fluorine Chem. 103 (2000) 123-127. https://doi.org/10.1016/S0022-1139(99)00312-7.

[25] Y. Liu, L. Jiang, H. Wang, H. Wang, W. Jiao, G. Chen, P. Zhang, D. Hui, X. Jian, A brief review for fluorinated carbon: synthesis, properties and applications, Nanotechnol. Rev. 8 (2019) 573-586. https://doi.org/10.1515/ntrev-2019-0051.

[26] H. Touhara, F. Okino, Property control of carbon materials by fluorination, Carbon. 38 (2000) 241-267. https://doi.org/10.1016/S0008-6223(99)00140-2.

[27] A. Tressaud, E. Durand, C. Labrugère, A.P. Kharitonov, L.N. Kharitonova, Modification of surface properties of carbon-based and polymeric materials through fluorination routes: From fundamental research to industrial applications, J. Fluorine Chem. 128 (2007) 378-391. https://doi.org/10.1016/j.jfluchem.2006.12.015.

[28] Y.-S. Lee, Syntheses and properties of fluorinated carbon materials, J. Fluorine Chem. 128 (2007) 392-403. https://doi.org/10.1016/j.jfluchem.2006.11.014.

[29] J. Giraudet, M. Dubois, K. Guérin, C. Delabarre, A. Hamwi, F. Masin, Solid-State NMR Study of the Post-Fluorination of $\left(\mathrm{C}_{2.5} \mathrm{~F}\right)_{n}$ Fluorine-GIC, J. Phys. Chem. B. 111 (2007) 14143-14151. https://doi.org/10.1021/jp076170g.

[30] M. Dubois, J. Giraudet, K. Guérin, A. Hamwi, Z. Fawal, P. Pirotte, F. Masin, EPR and Solid-State NMR Studies of Poly(dicarbon monofluoride) $\left(\mathrm{C}_{2} \mathrm{~F}\right)_{n}$, J. Phys. Chem. B. 110 (2006) 11800-11808. https://doi.org/10.1021/jp061291m.

[31] Y. Ahmad, K. Guérin, M. Dubois, W. Zhang, A. Hamwi, Enhanced performances in primary lithium batteries of fluorinated carbon nanofibers through static fluorination, Electrochim. Acta. 114 (2013) 142-151. https://doi.org/10.1016/j.electacta.2013.09.140.

[32] Y. Ahmad, N. Batisse, X. Chen, M. Dubois, Preparation and Applications of Fluorinated Graphenes, C. 7 (2021) 20. https://doi.org/10.3390/c7010020.

[33] F. Chamssedine, M. Dubois, K. Guérin, J. Giraudet, F. Masin, D.A. Ivanov, L. Vidal, R. Yazami, A. Hamwi, Reactivity of Carbon Nanofibers with Fluorine Gas, Chem. Mater. 19 (2007) 161-172. https://doi.org/10.1021/cm061731m.

[34] A. Hamwi, H. Alvergnat, S. Bonnamy, F. Béguin, Fluorination of carbon nanotubes, Carbon. 35 (1997) 723-728. https://doi.org/10.1016/S0008-6223(97)00013-4.

[35] Y. Ahmad, S. Berthon-Fabry, M. Chatenet, G. Monier, M. Dubois, K. Guerin, Advances in tailoring the water content in porous carbon aerogels using RT-pulsed fluorination, J. Fluorine Chem. 238 (2020) 109633. https://doi.org/10.1016/j.jfluchem.2020.109633.

[36] W. Zhang, K. Guérin, M. Dubois, Z.E. Fawal, D.A. Ivanov, L. Vidal, A. Hamwi, Carbon nanofibres fluorinated using TbF4 as fluorinating agent. Part I: Structural properties, Carbon. 46 (2008) 1010-1016. https://doi.org/10.1016/j.carbon.2008.02.029.

[37] W. Zhang, M. Dubois, K. Guérin, P. Bonnet, H. Kharbache, F. Masin, A.P. Kharitonov, A. Hamwi, Effect of curvature on $\mathrm{C}-\mathrm{F}$ bonding in fluorinated carbons: from fullerene and derivatives to graphite, Phys. Chem. Chem. Phys. 12 (2010) 1388-1398. https://doi.org/10.1039/B914853A. 
[38] D. Hegemann, H. Brunner, C. Oehr, Plasma treatment of polymers for surface and adhesion improvement, Nucl. Instrum. Meth. B. 208 (2003) 281-286. https://doi.org/10.1016/S0168-583X(03)00644-X.

[39] S. Mujin, H. Baorong, W. Yisheng, T. Ying, H. Weiqiu, D. Youxian, The surface of carbon fibres continuously treated by cold plasma, Compos. Sci. Technol. 34 (1989) 353-364. https://doi.org/10.1016/0266-3538(89)90004-3.

[40] I.H. Loh, R.E. Cohen, R.F. Baddour, Modification of carbon surfaces in cold plasmas, J. Mater. Sci. 22 (1987) 2937-2947. https://doi.org/10.1007/BF01086494.

[41] J.B. Donnet, M. Brendle, T.L. Dhami, O.P. Bahl, Plasma treatment effect on the surface energy of carbon and carbon fibers, Carbon. 24 (1986) 757-770. https://doi.org/10.1016/0008-6223(86)90186-7.

[42] S. Tiwari, J. Bijwe, Surface Treatment of Carbon Fibers - A Review, Procedia Technol. 14 (2014) 505-512. https://doi.org/10.1016/j.protcy.2014.08.064.

[43] A.L. Santos, E.C. Botelho, K.G. Kostov, P.A.P. Nascente, L.L.G. da Silva, Atmospheric Plasma Treatment of Carbon Fibers for Enhancement of Their Adhesion Properties, IEEE Trans. Plasma Sci. 41 (2013) 319-324. https://doi.org/10.1109/TPS.2012.2234484.

[44] Y. Zhao, C. Zhang, X. Shao, Y. Wang, Y. Qiu, Effect of Atmospheric Plasma Treatment on Carbon Fiber/Epoxy Interfacial Adhesion, J. Adhes. Sci. Technol. 25 (2011) 2897-2908. https://doi.org/10.1163/016942411X576572.

[45] J. Zhuoda, Effects of plasma treatment of carbon fibers on interfacial properties of BMI resin composites, Surf. Interface Anal. 51 (2019) 458-464. https://doi.org/10.1002/sia.6600.

[46] M. Baghery Borooj, A. Mousavi Shoushtari, E. Nosratian Sabet, A. Haji, Influence of oxygen plasma treatment parameters on the properties of carbon fiber, J. Adhes. Sci. Technol. 30 (2016) 2372-2382. https://doi.org/10.1080/01694243.2016.1182833.

[47] G.M. Wu, Oxygen plasma treatment of high performance fibers for composites, Mater. Chem. Phys. 85 (2004) 81-87. https://doi.org/10.1016/j.matchemphys.2003.12.004.

[48] H. Zhang, W. Li, Plasma-grafting polymerization on carbon fibers and its effect on their composite properties, Appl. Surf. Sci. 356 (2015) 492-498. https://doi.org/10.1016/j.apsusc.2015.08.016.

[49] C. Cardinaud, Fluorine-based plasmas: Main features and application in micro-and nanotechnology and in surface treatment, C. R. Chim. 21 (2018) 723-739. https://doi.org/10.1016/j.crci.2018.01.009.

[50] H. Kasai, M. Kogoma, T. Moriwaki, S. Okazaki, Surface structure estimation by plasma fluorination of amorphous carbon, diamond, graphite and plastic film surfaces, J. Phys. D: Appl. Phys. 19 (1986) 225-228. https://doi.org/10.1088/00223727/19/11/002.

[51] R.J. Lagow, L.A. Shimp, D.K. Lam, R.F. Baddour, Synthesis of poly(carbon monofluoride) in a fluorine plasma, Inorg. Chem. 11 (1972) 2568-2570. https://doi.org/10.1021/ic50116a063.

[52] A. Fridman, Plasma Chemistry, Cambridge University Press, Cambridge, 2008. https://doi.org/10.1017/CBO9780511546075.

[53] A.P. Kharitonov, G.V. Simbirtseva, A. Tressaud, E. Durand, C. Labrugère, M. Dubois, Comparison of the surface modifications of polymers induced by direct fluorination and rf-plasma using fluorinated gases, J. Fluorine Chem. 165 (2014) 49-60. https://doi.org/10.1016/j.jfluchem.2014.05.002.

[54] K.K.C. Ho, A.F. Lee, A. Bismarck, Fluorination of carbon fibres in atmospheric plasma, Carbon. 45 (2007) 775-784. https://doi.org/10.1016/j.carbon.2006.11.015. 
[55] K.K.C. Ho, S. Lamoriniere, G. Kalinka, E. Schulz, A. Bismarck, Interfacial behavior between atmospheric-plasma-fluorinated carbon fibers and poly(vinylidene fluoride), J. Colloid. Interf. Sci. 313 (2007) 476-484. https://doi.org/10.1016/j.jcis.2007.04.076.

[56] K.K.C. Ho, A.F. Lee, S. Lamoriniere, A. Bismarck, Continuous atmospheric plasma fluorination of carbon fibres, Compos. Part A Appl. Sci. Manuf. 39 (2008) 364-373. https://doi.org/10.1016/j.compositesa.2007.10.008.

[57] M.Q. Tran, K.K.C. Ho, G. Kalinka, M.S.P. Shaffer, A. Bismarck, Carbon fibre reinforced poly(vinylidene fluoride): Impact of matrix modification on fibre/polymer adhesion, Compos. Sci. Technol. 68 (2008) 1766-1776. https://doi.org/10.1016/j.compscitech.2008.02.021.

[58] A. Bismarck, R. Tahhan, J. Springer, A. Schulz, T.M. Klapötke, H. Zeil, W. Michaeli, Influence of fluorination on the properties of carbon fibres, J. Fluorine Chem. 84 (1997) 127-134. https://doi.org/10.1016/S0022-1139(97)00029-8.

[59] S.-J. Park, M.-K. Seo, Y.-S. Lee, Surface characteristics of fluorine-modified PANbased carbon fibers, Carbon. 41 (2003) 723-730. https://doi.org/10.1016/S00086223(02)00384-6.

[60] R.B. Mathur, V. Gupta, O.P. Bahl, A. Tressaud, S. Flandrois, Improvement in the mechanical properties of polyacrylonitrile (PAN)- based carbon fibers after fluorination, Synth. Met. 114 (2000) 197-200. https://doi.org/10.1016/S03796779(00)00251-4.

[61] I. Kruppke, C. Scheffler, F. Simon, R.-D. Hund, C. Cherif, Surface Treatment of Carbon Fibers by Oxy-Fluorination, Materials. 12 (2019) 18. https://doi.org/10.3390/ma12040565.

[62] S.-J. Park, M.-K. Seo, K.-Y. Rhee, Studies on mechanical interfacial properties of oxyfluorinated carbon fibers-reinforced composites, Mater. Sci. Eng. A. 356 (2003) 219226. https://doi.org/10.1016/S0921-5093(03)00134-5.

[63] M.-K. Seo, S.-J. Park, Influence of oxyfluorination on physicochemical characteristics of carbon fibers and their reinforced epoxy composites, Macromol. Res. 17 (2009) 430-435. https://doi.org/10.1007/BF03218885.

[64] I.S. Lim, S.H. Yoo, I.N. Park, Y.S. Lee, Influence of Oxyfluorination on Properties of Polyacrylonitrile (PAN)- Based Carbon Fibers, Carbon lett. 5 (2004) 6.

[65] Y.-S. Lee, B.-K. Lee, J.-S. Rho, The physicochemical characteristics of modified carbon fibers by Fluorination, Korean J. Chem. Eng. 20 (2003) 151-156. https://doi.org/10.1007/BF02697201.

[66] Y.-S. Lee, B.-K. Lee, Surface properties of oxyfluorinated PAN-based carbon fibers, Carbon. 40 (2002) 2461-2468. https://doi.org/10.1016/S0008-6223(02)00152-5.

[67] K.K.C. Ho, G. Beamson, G. Shia, N.V. Polyakova, A. Bismarck, Surface and bulk properties of severely fluorinated carbon fibres, J. Fluorine Chem. 128 (2007) 13591368. https://doi.org/10.1016/j.jfluchem.2007.06.005.

[68] A. Tressaud, C. Guimon, V. Gupta, F. Moguet, Fluorine-intercalated carbon fibers: II: An X-ray photoelectron spectroscopy study, Mater. Sci. Eng., B. 30 (1995) 61-68. https://doi.org/10.1016/0921-5107(94)01141-9.

[69] J. Moosburger-Will, M. Bauer, E. Laukmanis, R. Horny, D. Wetjen, T. Manske, F. Schmidt-Stein, J. Töpker, S. Horn, Interaction between carbon fibers and polymer sizing: Influence of fiber surface chemistry and sizing reactivity, Applied Surface Science. 439 (2018) 305-312. https://doi.org/10.1016/j.apsusc.2017.12.251.

[70] F.R. Jones, A Review of Interphase Formation and Design in Fibre-Reinforced Composites, J Adhes Sci Technol. 24 (2010) 171-202. https://doi.org/10.1163/016942409X12579497420609. 
[71] R.L. Zhang, Y.D. Huang, L. Liu, Y.R. Tang, D. Su, L.W. Xu, Effect of emulsifier content of sizing agent on the surface of carbon fibres and interface of its composites, Appl. Surf. Sci. 257 (2011) 3519-3523. https://doi.org/10.1016/j.apsusc.2010.11.066.

[72] K.K.C. Ho, G. Kalinka, M.Q. Tran, N.V. Polyakova, A. Bismarck, Fluorinated carbon fibres and their suitability as reinforcement for fluoropolymers, Compos. Sci. Technol. 67 (2007) 2699-2706. https://doi.org/10.1016/j.compscitech.2007.02.012.

[73] J.-C. Agopian, O. Teraube, M. Dubois, K. Charlet, Fluorination of carbon fibre sizing without mechanical or chemical loss of the fibre, Appl. Surf. Sci. 534 (2020) 147647. https://doi.org/10.1016/j.apsusc.2020.147647.

[74] R.J. Lagow, J.L. Margrave, Direct Fluorination: A "New" Approach to Fluorine Chemistry, in: S.J. Lippard (Ed.), Progress in Inorganic Chemistry, John Wiley \& Sons, Inc., Hoboken, NJ, USA, 2007: pp. 161-210. https://doi.org/10.1002/9780470166277.ch3.

[75] A.P. Kharitonov, Direct fluorination of polymers, Nova Science Publishers, New York, 2008.

[76] A.P. Kharitonov, B.A. Loginov, Direct fluorination of polymer final products: From fundamental study to practical application, Russ. J. Gen. Chem. 79 (2009) 635-641. https://doi.org/10.1134/S1070363209030451.

[77] A.P. Kharitonov, Improvement of Performance Characteristics of Polymer Materials by Direct Fluorination, Chemistry for Sustainable Development. 12 (2004) 625-630.

[78] A.P. Kharitonov, R. Taege, G. Ferrier, V.V. Teplyakov, D.A. Syrtsova, G.-H. Koops, Direct fluorination - Useful tool to enhance commercial properties of polymer articles, J. Fluorine Chem. 126 (2005) 251-263. https://doi.org/10.1016/j.jfluchem.2005.01.016.

[79] A.P. Kharitonov, Direct fluorination of polymers - From fundamental research to industrial applications, Prog. Org. Coat. 61 (2008) 192-204. https://doi.org/10.1016/j.porgcoat.2007.09.027.

[80] A.P. Kharitonov, R. Taege, G. Ferrier, N.P. Piven, The kinetics and mechanism of the direct fluorination of polyethylenes, Surf. Coat. Int. B: Coat. Trans. 88 (2005) 201-212. https://doi.org/10.1007/BF02699574.

[81] W. Feng, P. Long, Y. Feng, Y. Li, Two-Dimensional Fluorinated Graphene: Synthesis, Structures, Properties and Applications, Adv. Sci. 3 (2016) 1500413. https://doi.org/10.1002/advs.201500413.

[82] J.D.H. Hughes, The carbon fibre/epoxy interface - A review, Compos Sci Technol. 41 (1991) 13-45. https://doi.org/10.1016/0266-3538(91)90050-Y.

[83] S.R. Taylor, Coatings for Corrosion Protection: Inorganic, in: Encyclopedia of Materials: Science and Technology, Elsevier, 2001: pp. 1263-1269. https://doi.org/10.1016/B0-08-043152-6/00238-2.

[84] I. Velo-Gala, J.J. López-Peñalver, M. Sánchez-Polo, J. Rivera-Utrilla, Surface modifications of activated carbon by gamma irradiation, Carbon. 67 (2014) 236-249. https://doi.org/10.1016/j.carbon.2013.09.087.

[85] A. Kuwabara, S. Kuroda, H. Kubota, Polymer Surface Treatment by Atmospheric Pressure Low Temperature Surface Discharge Plasma: Its Characteristics and Comparison with Low Pressure Oxygen Plasma Treatment, Plasma Sci. Technol. 9 (2007) 181-189. https://doi.org/10.1088/1009-0630/9/2/14.

[86] A. Morais, J.P.C. Alves, F.A.S. Lima, M. Lira-Cantu, A.F. Nogueira, Enhanced photovoltaic performance of inverted hybrid bulk-heterojunction solar cells using TiO 2 /reduced graphene oxide films as electron transport layers, J. Photon. Energy. 5 (2015). https://doi.org/10.1117/1.JPE.5.057408.

[87] S. Tunma, K. Inthanon, C. Chaiwong, J. Pumchusak, W. Wongkham, D. Boonyawan, Improving the attachment and proliferation of umbilical cord mesenchymal stem cells 
on modified polystyrene by nitrogen-containing plasma, Cytotechnology. 65 (2013) 119-134. https://doi.org/10.1007/s10616-012-9467-9.

[88] D. Kumari, L. Sheikh, S. Bhattacharya, T. Webster, S. Nayar, Two-dimensional collagen-graphene as colloidal templates for biocompatible inorganic nanomaterial synthesis, Int. J. Nanomedicine. Volume 12 (2017) 3605-3616. https://doi.org/10.2147/IJN.S133833.

[89] S. Farzadnia, R.D. Nimmagadda, C. McRae, A comparative structural study of nitrogen-rich fulvic acids from various Antarctic lakes, Environ. Chem. 14 (2017) 502. https://doi.org/10.1071/EN17095.

[90] G.P. López, D.G. Castner, B.D. Ratner, XPS O 1s binding energies for polymers containing hydroxyl, ether, ketone and ester groups, Surf. Interface Anal. 17 (1991) 267-272. https://doi.org/10.1002/sia.740170508.

[91] Y.-T. Tseng, H.-Y. Lu, J.-R. Li, W.-J. Tung, W.-H. Chen, L.-K. Chau, Facile Functionalization of Polymer Surfaces in Aqueous and Polar Organic Solvents via 3Mercaptopropylsilatrane, ACS Appl. Mater. Interfaces. 8 (2016) 34159-34169. https://doi.org/10.1021/acsami.6b13926.

[92] E. Gonzalez, R.F. Hicks, Surface Analysis of Polymers Treated by Remote Atmospheric Pressure Plasma, Langmuir. 26 (2010) 3710-3719. https://doi.org/10.1021/la9032018.

[93] G. Apai, W.P. McKenna, Surface analysis of polycarbonate thin films by HighResolution Electron Energy Loss Spectroscopy. Negative ion resonances and surface vibrations, Langmuir. 7 (1991) 2266-2272. https://doi.org/10.1021/la00058a048.

[94] Y.C.G. Kwan, G.M. Ng, C.H.A. Huan, Identification of functional groups and determination of carboxyl formation temperature in graphene oxide using the XPS O 1s spectrum, Thin Solid Films. 590 (2015) 40-48. https://doi.org/10.1016/j.tsf.2015.07.051.

[95] W. Zhang, M. Dubois, K. Guérin, P. Bonnet, E. Petit, N. Delpuech, D. Albertini, F. Masin, A. Hamwi, Effect of graphitization on fluorination of carbon nanocones and nanodiscs, Carbon. 47 (2009) 2763-2775. https://doi.org/10.1016/j.carbon.2009.05.035.

[96] V. Gupta, R.B. Mathur, O.P. Bahl, A. Tressaud, S. Flandrois, Thermal stability of fluorine-intercalated carbon fibres, Synth. Met. 73 (1995) 69-75. https://doi.org/10.1016/0379-6779(95)03299-1.

[97] A. Bosak, A. Dideikin, M. Dubois, O. Ivankov, E. Lychagin, A. Muzychka, G. Nekhaev, V. Nesvizhevsky, A. Nezvanov, R. Schweins, A. Strelkov, A. Vul', K. Zhernenkov, Fluorination of Diamond Nanoparticles in Slow Neutron Reflectors Does Not Destroy Their Crystalline Cores and Clustering While Decreasing Neutron Losses, Materials. 13 (2020) 3337. https://doi.org/10.3390/ma13153337.

[98] C. Cavallari, M. Brunelli, S. Radescu, M. Dubois, N. Batisse, G.B.M. Vaughan, H.E. Fischer, V. Pischedda, Structural and electronic changes in graphite fluorides as a function of fluorination rate: An XRS, PDF and DFT study, Carbon. 147 (2019) 1-8. https://doi.org/10.1016/j.carbon.2019.02.053.

[99] K. Guérin, J.P. Pinheiro, M. Dubois, Z. Fawal, F. Masin, R. Yazami, A. Hamwi, Synthesis and Characterization of Highly Fluorinated Graphite Containing sp ${ }^{2}$ and $\mathrm{sp}^{3}$ Carbon, Chem. Mater. 16 (2004) 1786-1792. https://doi.org/10.1021/cm034974c.

[100] L.G. Bulusheva, Y.V. Fedoseeva, E. Flahaut, J. Rio, C.P. Ewels, V.O. Koroteev, G. Van Lier, D.V. Vyalikh, A.V. Okotrub, Effect of the fluorination technique on the surface-fluorination patterning of double-walled carbon nanotubes, Beilstein J. Nanotechnol. 8 (2017) 1688-1698. https://doi.org/10.3762/bjnano.8.169. 
[101] V. Gupta, T. Nakajima, Y. Ohzawa, B. Žemva, A study on the formation mechanism of graphite fluorides by Raman spectroscopy, J. Fluorine Chem. 120 (2003) 143-150. https://doi.org/10.1016/S0022-1139(02)00323-8.

[102] N. Watanabe, Two types of graphite fluorides, (CF)n and (C2F)n, and discharge characteristics and mechanisms of electrodes of (CF)n and (C2F)n in lithium batteries, Solid State Ionics. 1 (1980) 87-110. https://doi.org/10.1016/0167-2738(80)90025-9.

[103] K. Guérin, M. Dubois, A. Houdayer, A. Hamwi, Applicative performances of fluorinated carbons through fluorination routes: A review, J. Fluorine Chem. 134 (2012) 11-17. https://doi.org/10.1016/j.jfluchem.2011.06.013.

[104] Y. Sato, K. Itoh, R. Hagiwara, T. Fukunaga, Y. Ito, On the so-called "semi-ionic" C-F bond character in fluorine-GIC, Carbon. 42 (2004) 3243-3249. https://doi.org/10.1016/j.carbon.2004.08.012.

[105] W. Zhang, P. Bonnet, M. Dubois, C.P. Ewels, K. Guérin, E. Petit, J.-Y. Mevellec, L. Vidal, D.A. Ivanov, A. Hamwi, Comparative Study of SWCNT Fluorination by Atomic and Molecular Fluorine, Chem. Mater. 24 (2012) 1744-1751. https://doi.org/10.1021/cm203415e.

[106] S. Osuna, M. Torrent-Sucarrat, M. Solà, P. Geerlings, C.P. Ewels, G.V. Lier, Reaction Mechanisms for Graphene and Carbon Nanotube Fluorination, J. Phys. Chem. C. 114 (2010) 3340-3345. https://doi.org/10.1021/jp908887n.

[107] G. Van Lier, C.P. Ewels, F. Zuliani, A. De Vita, J.-C. Charlier, Theoretical Analysis of Fluorine Addition to Single-Walled Carbon Nanotubes: Functionalization Routes and Addition Patterns, J. Phys. Chem. B. 109 (2005) 6153-6158. https://doi.org/10.1021/jp046005q.

[108] J.-P. Boudou, J.I. Paredes, A. Cuesta, A. Martinez-Alonso, J.M.D. Tascon, Oxygen plasma modification of pitch-based isotropic carbon fibres, Carbon. 41 (2003) 41-56. https://doi.org/10.1016/S0008- 6223(02)00270-1.

[109] M. Zayat, D. Davidov, H. Selig, Fluorination of carbon fibers by halogen fluorides, Carbon. 32 (1994) 485-491. https://doi.org/10.1016/0008-6223(94)90170-8.

[110] Y. Sato, K. Itoh, R. Hagiwara, T. Fukunaga, Y. Ito, Short-range structures of poly(dicarbon monofluoride) (C2F)n and poly(carbon monofluoride) (CF)n, Carbon. 42 (2004) 2897-2903. https://doi.org/10.1016/j.carbon.2004.06.042.

[111] Y. Kita, N. Watanabe, Y. Fujii, Chemical composition and crystal structure of graphite fluoride, J. Am. Chem. Soc. 101 (1979) 3832-3841. https://doi.org/10.1021/ja00508a020.

[112] D.D.L. Chung, Carbon fiber composites, Butterworth-Heinemann, 1994.

[113] Y. Chong, H. Ohara, Modification of carbon fiber surfaces by direct fluorination, J. Fluorine Chem. 57 (1992) 169-175. https://doi.org/10.1016/S0022-1139(00)82829-8.

[114] G. Li, K. Kaneko, S. Ozeki, F. Okino, H. Touhara, Water Rejective Nature of Fluorinated Microporous Carbon Fibers, Langmuir. 11 (1995) 716-717. https://doi.org/10.1021/la00003a008.

[115] J.A. Menéndez, M.J. Illán-Gómez, C.A.L. y León, L.R. Radovic, On the difference between the isoelectric point and the point of zero charge of carbons, Carbon. 33 (1995) 1655-1657. https://doi.org/10.1016/0008-6223(95)96817-R.

[116] A. Tressaud, T. Shirasaki, G. Nansé, E. Papirer, Fluorinated carbon blacks: influence of the morphology of the starting material on the fluorination mechanism, Carbon. 40 (2002) 217-220. https://doi.org/10.1016/S0008-6223(01)00177-4.

[117] G.A. Zickler, B. Smarsly, N. Gierlinger, H. Peterlik, O. Paris, A reconsideration of the relationship between the crystallite size La of carbons determined by X-ray diffraction and Raman spectroscopy, Carbon. 44 (2006) 3239-3246.

https://doi.org/10.1016/j.carbon.2006.06.029. 
[118] Z. Xu, Z. He, Y. Song, X. Fu, M. Rommel, X. Luo, A. Hartmaier, J. Zhang, F. Fang, Topic Review: Application of Raman Spectroscopy Characterization in Micro/NanoMachining, Micromachines. 9 (2018) 361. https://doi.org/10.3390/mi9070361.

[119] T. Smausz, B. Kondász, T. Gera, T. Ajtai, N. Utry, M. Pintér, G. Kiss-Albert, J. Budai, Z. Bozóki, G. Szabó, B. Hopp, Determination of UV-visible-NIR absorption coefficient of graphite bulk using direct and indirect methods, Appl. Phys. A. 123 (2017) 633. https://doi.org/10.1007/s00339-017-1249-y.

[120] A. Tressaud, V. Gupta, L. Piraux, L. Lozano, E. Marquestaut, S. Flandrois, A. Marchand, O.P. Bahl, Fluorine-intercalated carbon fibers - Structural and transport properties, Carbon. 32 (1994) 1485-1492. https://doi.org/10.1016/00086223(94)90143-0.

[121] L. Fischer, U. Siemann, W. Ruland, Structure and properties of fluorinated carbon fibers, Colloid Polym. Sci. 261 (1983) 744-749. https://doi.org/10.1007/BF01410948.

[122] L.T. Drzal, The interphase in epoxy composites, in: K. Dušek (Ed.), Epoxy Resins and Composites II, Springer-Verlag, 1986: pp. 1-32. https://doi.org/10.1007/BFb0017913.

[123] L.T. Drzal, M. Madhukar, Fibre-matrix adhesion and its relationship to composite mechanical properties, J. Mater. Sci. 28 (1993) 569-610. https://doi.org/10.1007/BF01151234.

[124] J. Schultz, L. Lavielle, C. Martin, The Role of the Interface in Carbon Fibre-Epoxy Composites, J. Adhes. 23 (1987) 45-60. https://doi.org/10.1080/00218468708080469.

[125] M.S. Sohn, X.Z. Hu, J.K. Kim, L. Walker, Impact damage characterisation of carbon fibre/epoxy composites with multi-layer reinforcement, Compos. B. Eng. (2000) 681691. https://doi.org/10.1016/S1359-8368(00)00028-7.

[126] A.G. Bannov, O. Jašek, J. Prášek, J. Buršík, L. Zajíčková, Enhanced Ammonia Adsorption on Directly Deposited Nanofibrous Carbon Films, J. Sens. 2018 (2018) 114. https://doi.org/10.1155/2018/7497619.

[127] X. Feng, S. Irle, H. Witek, K. Morokuma, R. Vidic, E. Borguet, Sensitivity of Ammonia Interaction with Single-Walled Carbon Nanotube Bundles to the Presence of Defect Sites and Functionalities, J. Am. Chem. Soc. 127 (2005) 10533-10538. https://doi.org/10.1021/ja042998u.

[128] E. Bekyarova, M. Davis, T. Burch, M.E. Itkis, B. Zhao, S. Sunshine, R.C. Haddon, Chemically Functionalized Single-Walled Carbon Nanotubes as Ammonia Sensors, J. Phys. Chem. B. 108 (2004) 19717-19720. https://doi.org/10.1021/jp0471857.

[129] F. Rigoni, G. Drera, S. Pagliara, A. Goldoni, L. Sangaletti, High sensitivity, moisture selective, ammonia gas sensors based on single-walled carbon nanotubes functionalized with indium tin oxide nanoparticles, Carbon. 80 (2014) 356-363. https://doi.org/10.1016/j.carbon.2014.08.074.

[130] L.A. Panes-Ruiz, M. Shaygan, Y. Fu, Y. Liu, V. Khavrus, S. Oswald, T. Gemming, L. Baraban, V. Bezugly, G. Cuniberti, Toward Highly Sensitive and Energy Efficient Ammonia Gas Detection with Modified Single-Walled Carbon Nanotubes at Room Temperature, ACS Sens. 3 (2018) 79-86. https://doi.org/10.1021/acssensors.7b00358.

[131] G. Chimowa, Z.P. Tshabalala, A.A. Akande, G. Bepete, B. Mwakikunga, S.S. Ray, E.M. Benecha, Improving methane gas sensing properties of multi-walled carbon nanotubes by vanadium oxide filling, Sens. Actuators B Chem. 247 (2017) 11-18. https://doi.org/10.1016/j.snb.2017.02.167.

[132] Y. Lu, J. Li, J. Han, H.-T. Ng, C. Binder, C. Partridge, M. Meyyappan, Room temperature methane detection using palladium loaded single-walled carbon nanotube sensors, Chem. Phys. Lett. 391 (2004) 344-348. https://doi.org/10.1016/j.cplett.2004.05.029. 
[133] C. Struzzi, M. Scardamaglia, J. Casanova-Chafer, R. Calavia, J.-F. Colomer, A. Kondyurin, M. Bilek, N. Britun, R. Snyders, E. Llobet, C. Bittencourt, Exploiting sensor geometry for enhanced gas sensing properties of fluorinated carbon nanotubes under humid environment, Sens. Actuators B Chem. 281 (2019) 945-952. https://doi.org/10.1016/j.snb.2018.10.159.

[134] R. Afrin, N.A. Shah, Room temperature gas sensors based on carboxyl and thiol functionalized carbon nanotubes buckypapers, Diam. Relat. Mater. 60 (2015) 42-49. https://doi.org/10.1016/j.diamond.2015.10.010.

[135] J. Mäklin, T. Mustonen, K. Kordás, S. Saukko, G. Tóth, J. Vähäkangas, Nitric oxide gas sensors with functionalized carbon nanotubes, Phys. Stat. Sol. (B). 244 (2007) 4298-4302. https://doi.org/10.1002/pssb.200776118.

[136] A. Bannov, A. Manakhov, Plasma functionalization of multi-walled carbon nanotubes for ammonia gas sensors, in: Proceedings of 7th International Electronic Conference on Sensors and Applications, MDPI, 2020: p. 8175. https://doi.org/10.3390/ecsa-7-08175.

[137] A.G. Bannov, O. Jasek, A. Manakhov, M. Marik, D. Necas, L. Zajickova, HighPerformance Ammonia Gas Sensors Based on Plasma Treated Carbon Nanostructures, IEEE Sensors J. 17 (2017) 1964-1970. https://doi.org/10.1109/JSEN.2017.2656122.

[138] A. Karakuscu, L.-H. Hu, A. Ponzoni, C. Baratto, R. Ceccato, G. Sberveglieri, R. Raj, SiOCN Functionalized Carbon Nanotube Gas Sensors for Elevated Temperature Applications, J. Am. Ceram. Soc. 98 (2015) 1142-1149. https://doi.org/10.1111/jace.13396.

[139] Z. Zanolli, R. Leghrib, A. Felten, J.-J. Pireaux, E. Llobet, J.-C. Charlier, Gas Sensing with Au-Decorated Carbon Nanotubes, ACS Nano. 5 (2011) 4592-4599. https://doi.org/10.1021/nn200294h.

[140] S. Tang, W. Chen, H. Zhang, Z. Song, Y. Li, Y. Wang, The Functionalized SingleWalled Carbon Nanotubes Gas Sensor With Pd Nanoparticles for Hydrogen Detection in the High-Voltage Transformers, Front. Chem. 8 (2020) 174. https://doi.org/10.3389/fchem.2020.00174.

[141] V.M. Aroutiounian, Gas sensors based on functionalized carbon nanotubes, J. Contemp. Phys. 50 (2015) 333-354. https://doi.org/10.3103/S1068337215040064.

[142] V.I. Sysoev, A.V. Okotrub, I.P. Asanov, P.N. Gevko, L.G. Bulusheva, Advantage of graphene fluorination instead of oxygenation for restorable adsorption of gaseous ammonia and nitrogen dioxide, Carbon. 118 (2017) 225-232. https://doi.org/10.1016/j.carbon.2017.03.026.

[143] M.V. Katkov, V.I. Sysoev, A.V. Gusel'nikov, I.P. Asanov, L.G. Bulusheva, A.V. Okotrub, A backside fluorine-functionalized graphene layer for ammonia detection, Phys. Chem. Chem. Phys. 17 (2015) 444-450. https://doi.org/10.1039/C4CP03552F.

[144] Y. Liu, T.-T. Shi, T. Chen, W.-J. He, M.-M. Chen, D. Cao, The naked-eye NH3 sensor based on fluorinated graphene, Sens. Actuators B Chem. 281 (2019) 789-794. https://doi.org/10.1016/j.snb.2018.11.018.

[145] A.G. Bannov, M.V. Popov, A.E. Brester, P.B. Kurmashov, Recent Advances in Ammonia Gas Sensors Based on Carbon Nanomaterials, Micromachines. 12 (2021) 186. https://doi.org/10.3390/mi12020186.

[146] Y.H. Kim, J.S. Park, Y.-R. Choi, S.Y. Park, S.Y. Lee, W. Sohn, Y.-S. Shim, J.-H. Lee, C.R. Park, Y.S. Choi, B.H. Hong, J.H. Lee, W.H. Lee, D. Lee, H.W. Jang, Chemically fluorinated graphene oxide for room temperature ammonia detection at ppb levels, J. Mater. Chem. A. 5 (2017) 19116-19125. https://doi.org/10.1039/C7TA05766K.

[147] K.K. Tadi, S. Pal, T.N. Narayanan, Fluorographene based Ultrasensitive Ammonia Sensor, Sci. Rep. 6 (2016) 25221. https://doi.org/10.1038/srep25221. 
[148] H. Zhang, L. Fan, H. Dong, P. Zhang, K. Nie, J. Zhong, Y. Li, J. Guo, X. Sun, Spectroscopic Investigation of Plasma-Fluorinated Monolayer Graphene and Application for Gas Sensing, ACS Appl. Mater. Interfaces. 8 (2016) 8652-8661. https://doi.org/10.1021/acsami.5b11872.

[149] W. Kang, S. Li, Preparation of fluorinated graphene to study its gas sensitivity, RSC Adv. 8 (2018) 23459-23467. https://doi.org/10.1039/C8RA03451F.

[150] V. Urbanová, F. Karlický, A. Matěj, F. Šembera, Z. Janoušek, J.A. Perman, V. Ranc, K. Čépe, J. Michl, M. Otyepka, R. Zbořil, Fluorinated graphenes as advanced biosensors - effect of fluorine coverage on electron transfer properties and adsorption of biomolecules, Nanoscale. 8 (2016) 12134-12142. https://doi.org/10.1039/C6NR00353B.

[151] A.R. Thiruppathi, B. Sidhureddy, W. Keeler, A. Chen, Facile one-pot synthesis of fluorinated graphene oxide for electrochemical sensing of heavy metal ions, Electrochem. Commun. 76 (2017) 42-46. https://doi.org/10.1016/j.elecom.2017.01.015.

[152] S. Hajian, X. Zhang, P. Khakbaz, S.-M. Tabatabaei, D. Maddipatla, B.B. Narakathu, R.G. Blair, M.Z. Atashbar, Development of a Fluorinated Graphene-Based Resistive Humidity Sensor, IEEE Sensors J. 20 (2020) 7517-7524. https://doi.org/10.1109/JSEN.2020.2985055.

[153] M.-S. Park, K.H. Kim, M.-J. Kim, Y.-S. Lee, NH3 gas sensing properties of a gas sensor based on fluorinated graphene oxide, Colloids Surf. A Physicochem. Eng. Asp. 490 (2016) 104-109. https://doi.org/10.1016/j.colsurfa.2015.11.028. 